\title{
CONTRIBUCIÓN DEL PADRE FEIJOO A LA FÁBRICA DE LA NUEVA IGLESIA DEL MONASTERIO DE SAN JULIÁN DE SAMOS (LUGO): UN CAPÍTULO DOCUMENTADO DE LA HISTORIA DE LA ARQUITECTURA Y DE LA EDICIÓN DE LIBROS EN ESPAÑA*
}

\author{
JAVIER GONZÁLEZ SANTOS \\ Universidad de Oviedo \\ ORCID iD: http://orcid.org/0000-0002-3361-619X
}

\begin{abstract}
* Estoy en deuda (de gratitud, se entiende) con mi colega don Antonio José Meilán García, de la Universidad de Oviedo, por proveerme de erudición samonense, mindoniense y lucense, y verter o resumo al galego; con doña Ana María Herrero Montero, del Archivo Municipal de Oviedo, y con mi colega don Ángel Sicart Jiménez, de la Universidad de Santiago de Compostela, por facilitarme algunas de las fotografías antiguas con que se ilustra este trabajo. A don José Luis Seoane (del Departamento de Geografía de la Universidad de Oviedo) se debe la digitalización de la planta del monasterio de Samos publicada por Miguel Durán. La traducción al inglés y otras cosas son de Sylvia Montes Vigón. Asimismo, deseo agradecer formalmente las atenciones que me dispensó el prior de Samos, el padre fray José Luis Vélez Álvarez, en la visita que realicé al monasterio los días 5 y 6 de octubre de 2012.
\end{abstract}

Copyright: (C) 2017 CSIC. Este es un artículo de acceso abierto distribuido bajo los términos de una licencia de uso y distribución Creative Commons Attribution (CC-by) España 3.0.

Cómo citar/Citation: Javier GonzÁlez SAntos, "Contribución del Padre Feijoo a la fábrica de la nueva iglesia del monasterio de San Julián de Samos (Lugo): un capítulo documentado de la historia de la arquitectura y de la edición de libros en España", Cuadernos de Estudios Gallegos, 64, núm. 130 (2017), págs. 313-356, DOI: http://dx.doi.org/10.3989/ceg.2017.130.09 


\section{CONTRIBUCIÓN DEL PADRE FEIJOO A LA FÁBRICA DE LA NUEVA IGLESIA DEL MONASTERIO DE SAN JULIÁN DE SAMOS (LUGO): UN CAPÍTULO DOCUMENTADO DE LA HISTORIA DE LA ARQUITECTURA Y DE LA EDICIÓN DE LIBROS EN ESPAÑA RESUMEN}

La conclusión del monumental templo monasterial de San Julián de Samos (Lugo) en 1748 fue posible gracias a la cesión de los derechos de impresión y reimpresión y los beneficios de la venta de los seis primeros tomos del Theatro Crítico Universal $(1726,1728,1729,1730,1733$ y 1734) y de la Ilustración apologética (1729) que en 1734 el padre Benito Jerónimo Feijoo (1676-1764) hizo a la que había sido la casa de su noviciado y profesión religiosa (1690 y 1692). El dato era conocido de la erudición, pues ya dio noticias el padre fray Martín Sarmiento, amigo y corresponsal de Feijoo además de cronista de la orden benedictina, en un informe manuscrito de 1743 (publicado en 1879), y fray Eladio de Nóboa (1765) $\mathrm{y}$, a partir de ellos, se ha venido repitiendo, aunque sin convicción. Publicamos ahora ese documento de 1734 y, a su vista y de la obra literaria del padre Feijoo, hacemos algunas observaciones sobre la fábrica barroca del monasterio de Samos.

Palabras clave: monasterio de San Julián y Santa Basilisa de Samos (Lugo). Benito Jerónimo Feijoo; Theatro Crítico Universal e Ilustración apologética. Fray Pedro Martínez de Cardeña y fray Juan Vázquez (o fray Juan de Samos), arquitectos. Arquitectura barroca. Monasterios benedictinos en Galicia.

\section{CONTRIBUCIÓN DO PADRE FEIJOO Á FÁBRICA DA NOVA IGREXA DO MOSTEIRO DE SAN XULIÁN DE SAMOS (LUGO): UN CAPÍTULO DOCUMENTADO DA HISTORIA DA ARQUITECTURA E DA EDICIÓN DE LIBROS EN ESPAÑA}

Resumo

A conclusión do monumental templo mosteiral de San Xulián de Samos (Lugo) en 1748 foi posible grazas á cesión dos dereitos de impresión e reimpresión e os beneficios da venda dos seis primeiros tomos do Theatro Crítico Universal (1726, 1728, 1729, 1730, 1733 y 1734) e da Ilustración apologética (1729) que en 1734 o padre Benito Jerónimo Feijoo (1676-1764) fixo á que fora a casa do seu noviciado e profesión relixiosa (1690 y 1692). O dato era coñecido da erudición, pois xa dera noticias o padre frei Martín Sarmiento, amigo e correspondente de Feijoo, ademais de cronista da orden benedictina, nun informe manuscrito de 1743 (publicado en 1879), e frei Eladio de Nóboa (1765) e, a partir deles, veuse repetindo, aínda que sen convición. Publicamos agora ese documento de 1734 e, á súa vista e da obra literaria do padre Feijoo, facemos algunhas observacións sobre a fábrica barroca do mosteiro de Samos. Palabras clave: mosteiro de San Xulián e Santa Basilisa de Samos (Lugo). Benito Jerónimo Feijoo; Theatro Crítico Universal e Ilustración apologética. Frei Pedro Martínez de Cardeña e frei Juan Vázquez (ou frei Juan de Samos), arquitectos. Arquitectura barroca. Mosteiros benedictinos en Galicia.

\section{FATHER FEIJOO'S CONTRIBUTION TO THE BUILDING OF THE NEW CHURCH OF THE MONASTERY OF SAINT JULIAN OF SAMOS (LUGO, SPAIN): A DOCUMENTED CHAPTER OF THE HISTORY OF ARCHITECTURE AND BOOK PUBLISHING IN SPAIN}

\section{ABSTRACT}

The monastery temple of Saint Julian of Samos (Lugo) was concluded in 1748 thanks to the cession of printing and reprinting rights and the sale benefits of the first six volumes of Theatro Crítico Universal [Universal Critic Theatre] $(1726,1728,1729,1730,1733$ y 1734) and Ilustración apologética [Apologetic illustration ] (1729) done by Father Benito Jerónimo Feijoo (1676-1764) in 1734 to what had been the house where he had taken vows in 1690. The news was known by scholars since notice of it was given by Friar Martín Sarmiento, Feijoo's friend and correspondent as well as chronicler of the Benedictine Order, in a handwritten report of 1743 (published in 1879) and by Friar Eladio de Nóboa (1765) and repeated since then but with no conviction. We now publish this cession document of 1734 and from it and from father Feijoo's literary work, we make some comments about the baroque building of the Samos monastery. Key words: monastery of Saint Julian of Samos (Lugo). Benito Jerónimo Feijoo; Theatro Crítico Universal and Ilustración apologética. Friar Pedro Martínez de Cardeña and Friar Juan Vázquez (or Friar Juan of Samos), architects. Baroque architecture. Benedictine monasteries in Galicia. 
Recibido/Received: 04/05/2016

Aceptado/Accepted: 05/05/2017

In memoriam M. ${ }^{a}$ Dolores Mateos Dorado

(Salamanca, 1942-2015),

dieciochista, feijooniana y amiga.

$\mathrm{F}$

eijoo vistió la cogulla benedictina en el monasterio de San Julián de Samos a los catorce años cumplidos, el 16 de octubre de 1690, siendo abad fray Anselmo de la Peña, y en esta casa hizo el noviciado hasta que en 1692 cumplió los dieciséis y pudo profesar' ${ }^{1}$.

Fue este abad, junto a fray José de Laguna (que le precedió en la dignidad), el iniciador de las obras de reedificación del nuevo monasterio de Samos (entre 1689 y 1693). Fray Anselmo, General de la Congregación en 1697-1701, fue desterrado a América por austrino en 1711 y murió en 1729, siendo obispo de Agrigento, en Sicilia, sede a la que había sido promovido por el emperador Carlos VI de Austria².

El cariño de Feijoo por Samos se concretó en 1734. Fue ese año, en 18 de septiembre, cuando en un gesto de altruismo insólito, poco repetido en nuestras latitudes, firmó en Oviedo una escritura de compromiso por la que cedía durante diez años el usufructo de la venta de los seis primeros tomos del Theatro Crítico

\footnotetext{
1 Benito Jerónimo Feijoo y Montenegro nació en Casdemiro (Santa María de Melías, Orense) el 8 de octubre de 1676 y falleció en el Real Colegio de San Vicente de Oviedo, el 26 de septiembre de 1764. [Benito Jerónimo Feıjoo], “Autobiografía del Rvmo. P. Feijóo”, Anales de la Universidad de Oviedo. Tomo IV - 1905-1907, Oviedo, Establecimiento Tipográfico, 1907, pág. 379. Plácido Arias, Historia del Real Monasterio de Samos, Santiago de Compostela, Imprenta, Lib. y Enc. del Seminario Conciliar, 1950, págs. 268-271. Ernest Zaragoza i PAscual, "Libros de gradas de benedictinos profesos en los monasterios de Lorenzana y Samos (1597-1834)”, Estudios Mindonienses, VI (1990), pág. 871. Maximino Arias Cuenllas, Historia del monasterio de San Julián de Samos, Samos (Lugo), Monasterio de Samos, 1992, págs. 255 y 531. Para su biografía, que está por reescribir, véase el estudio clásico de Ramón OTERO PEDRAYo, El padre Feijoo: su vida, doctrina e influencias, Orense, Instituto de Estudios Orensanos "Padre Feijoo", 1972 (los primeros pasos de Feijoo en Samos y circunstancias canónicas de la profesión, en las págs. 69-70).

2 Ernesto Zaragoza Pascual, "Abadologio del monasterio de San Julián de Samos (siglos VIII-Xx)", Estudios Mindonienses, XII (1996), pág. 489, núm. 95.
} 
Universal y de la Ilustración apologética para financiar la conclusión del nuevo templo de San Julián de Samos (Apéndices, documento 1).

Por entonces, la fama y crédito de Feijoo estaban en su apogeo y a su sombra se había renovado la actividad editorial española ${ }^{3}$, con una copiosa sucesión de escritos de impugnación y apologéticos a los que periódicamente el benedictino daba pábulo con la publicación de una nueva entrega del Theatro Crítico. El primer tomo de esta obra (que llegó a nueve, con la edición de un Suplemento en 1740-1741) vio la luz en Madrid en 1726. La Ilustración apologética al primero, y segundo tomo del Theatro Crítico lleva en el pie de imprenta la fecha de 1729, pero por Campomanes consta que se empezó a distribuir en 10 de enero de $1730^{4}$.

El abad fray José Pérez, excatedrático de Artes de la Universidad de Oviedo, es el que firma la "Aprobación" del tomo VI del Theatro Crítico Universal en Oviedo, el 16 de enero de 1734. Pero de nuevo por Campomanes (tomado de la Gaceta de Madrid) se sabe que se puso a la venta el 31 de agosto siguiente ${ }^{5}$, días antes del otorgamiento de esta escritura, por lo que esta edición príncipe pudo ser incluida en los términos temporales y condicionales del documento de traspaso.

Precisamente, el tomo III del Theatro Crítico Universal (Madrid, 1729) está dedicado al "Mui R. do P. Abad, y Santo Convento" de San Julián de Samos y va firmado en el monasterio de San Vicente de Oviedo, el 13 de diciembre de 1728. Es una bella página literaria (Otero Pedrayo la calificó de "inmortal") ${ }^{6}$ e incluye una poética descripción del enclave agreste y pintoresco donde se localiza el monasterio de su profesión, no exenta de erudición y de una sana crítica histórica, como no podía ser menos en los puntos de la pluma de tan sabio y ponderado personaje (Apéndices, documento 2).

\footnotetext{
3 Al respecto, véase François Lopez, "La obra de Feijoo en la historia de la edición española (siglo XVIII)", en Inmaculada Urzainqui (ed.), Feijoo, hoy. Semana Marañón 2000, Oviedo, Fundación Gregorio Marañón - Instituto Feijoo de Estudios del Siglo XVIII, 2003, págs. 317-320.

4 "Noticia de la Vida y Obras del M. I. y R. P. D. Fr. Benito Gerónimo Feijoo, Monge Benedictino de la Congregación de España, Catedrático de Prima de Teología Jubilado de la Universidad de Oviedo, Maestro General por su Orden, del Consejo de S. M.”, escrita por Pedro Rodríguez Campomanes; figura al frente del t. I de la reedición del Teatro Crítico Universal hecha por la Compañía de Impresores y Libreros del Reino (Madrid, Imprenta Real de la Gaceta, MdCCLXv [1765], pág. XL). Vicente de la Fuente, "Preliminares" a Obras escogidas del Padre Fray Benito Jerónimo Feijoo y Montenegro, Maestro general de la religión de San Benito, del Consejo de S. M., etc., etc. Con una Noticia de su vida y juicio crítico de sus obras, Madrid, M. Rivadeneyra - Impresor - Editor, 1863 (Biblioteca de Autores Españoles, desde la formación del lenguaje hasta nuestros días, t. LVI), pág. x. José Miguel CAso GonzÁlez y Silverio Cerra SuÁREz, Benito Jerónimo Feijoo. Obras completas. Tomo I. Bibliografia, Oviedo, Cátedra Feijoo - Centro de Estudios del Siglo XVIII, 1981, núm. 128 a, pág. 68.

5 Gaceta de Madrid, núm. 35, del martes 31 de agosto de 1734, pág. 176. [P. RodríGuez DE CAMPOMANEs], "Noticia de la Vida y Obras del M. I. y R. P. D. Fr. Benito Gerónimo Feijoo...”, pág. XLI. V. de la Fuente, "Preliminares", pág. XI. J. M. Caso y S. Cerra, Benito Jerónimo Feijoo. Bibliografía..., núm. 167 a, págs. 95-96.

6 R. Otero Pedrayo, El padre Feijoo..., pág. 259.
} 


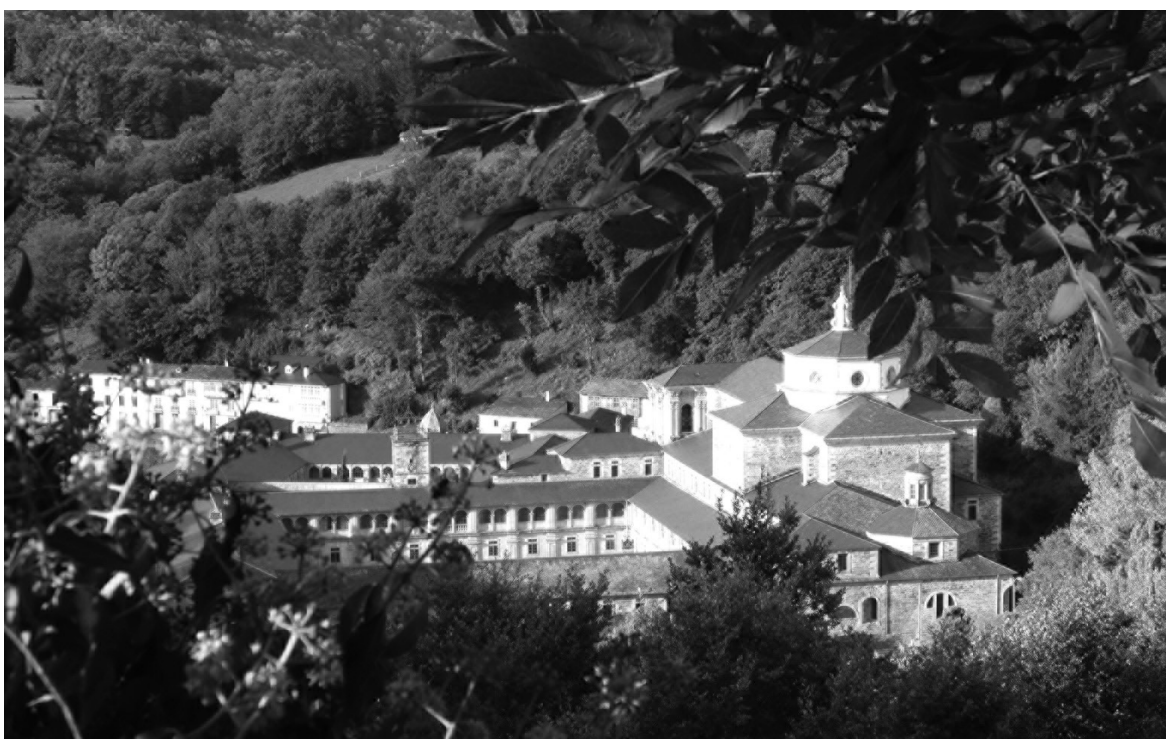

Panorámica del monasterio de San Julián de Samos desde el NE, por el camino que viene de Triacastela, que es el del Camino de Santiago. Fotografía del autor.

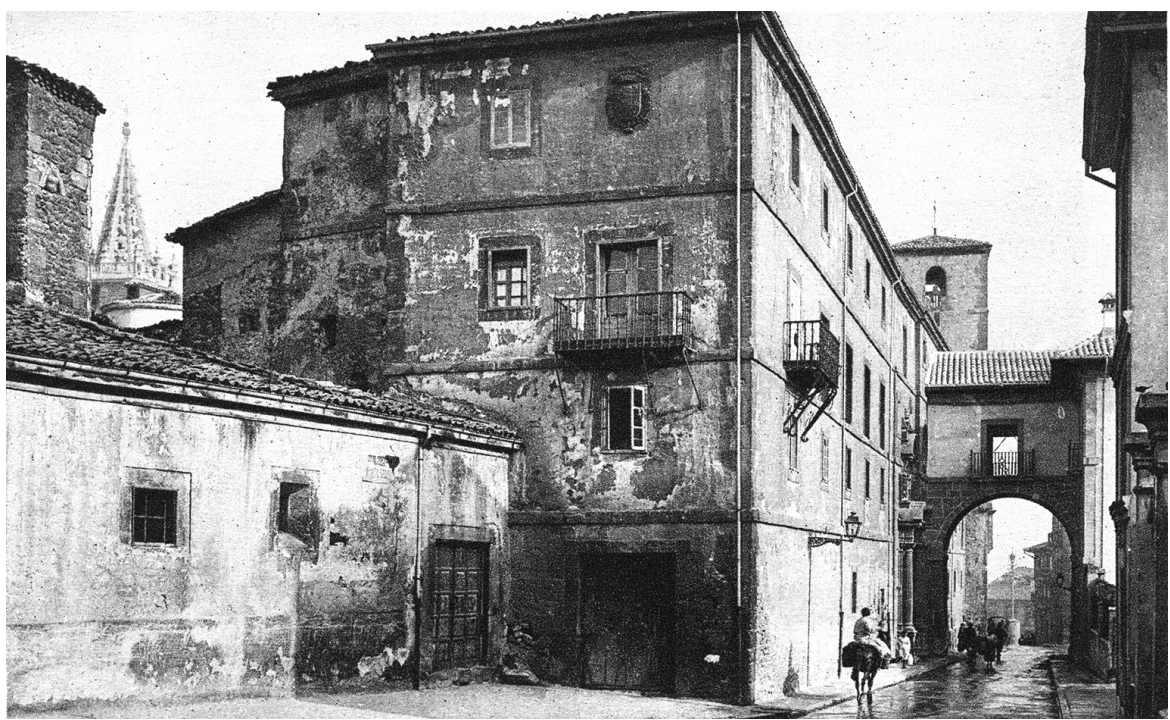

Antiguo monasterio de San Vicente de Oviedo y la calle y arco de San Vicente; en primer término, a la izquierda, la antigua capilla de los Peregrinos de la catedral de Oviedo y el pabellón de la celda abacial (demolidos en 1928). Fotografía de Lucien Roisin (París, 1884-Barcelona, 1943), Barcelona; tarjeta postal, $90 \times 134 \mathrm{~mm}$. Oviedo, Archivo Municipal de Oviedo (núm. de registro P-56). 
El PAdRe FeiJoo cede los DEREChos de EDICIÓN DE SUS OBRAS PARA LA CONCLUSIÓN DEL TEMPLO DE SAMOS

Este documento era desconocido, pero no sus consecuencias. Ya en 1743 (todavía dentro del plazo de usufructo del traspaso), fray Martín Sarmiento (Villafranca del Bierzo, 1695-Madrid, 1772), en un informe manuscrito que solo fue publicado en 1879, hacía referencia a que la construcción del templo de Samos se financiaba con la venta de las obras del padre Feijoo:

La $[$ casa] de Samos está casi fabricando Iglesia nueva, porque la antigua era mala, vieja, pequeña, y fabricada en falso. [...]

Por ser el P. Mtro. Feijóo, hijo profeso de la casa de Samos, cedióle en vida, para que ella pudiese proseguir la fábrica de su nueva iglesia, el uso de todo el útil que podrán producir todas las reimpresiones de sus escritos ${ }^{7}$.

Sobre el usufructo editorial de los escritos de Feijoo disertó en otra ocasión el padre Sarmiento. Así lo señalaba Antolín López: "Sarmiento defendió siempre que á Samos pertenecía el derecho de imprimir las obras de aquel sabio polígrafo, escribiendo, en 25 de Marzo de 1750 acerca de las condiciones con que debía hacer Feijoo la cesión de sus obras para las de la iglesia y sacristía del monasterio de Samos". Pero el documento citado nos es desconocido.

Y más adelante, uno de los panegiristas del Padre Maestro, fray Eladio de Nóboa, refiriéndose a las virtudes cristianas que revistieron en vida a Feijoo, dijo expresamente que una de ellas fue la caridad y que merced a su generosidad se pudo erigir la iglesia de Samos:

\footnotetext{
Fray Martín de SARmiento (OSB), Manifiesto del recibo de rentas de los monasterios, de la religión de San Benito; y en qué se emplean. Sacado y presentado al Consejo por el Rvmo. P. Mtro. Fr. Martín Sarmiento benedictino, Cronista General de su Religión: y de Indias por el Rey N. S.: en carta á un amigo que le consulta. Madrid. Año de 1743, Santiago, Biblioteca de "El Porvenir", 1879, págs. 115-116 y 117, respectivamente. Citado por Antolín LóPez PelÁEz (presb.), El monasterio de Samos. Estudio histórico. Con un M. S. inédito del P. Sarmiento, Lugo, Imprenta á cargo de Juan M. Bravo, 1894, págs. 135-137; Antonio Bonet Correa, La arquitectura en Galicia durante el siglo XVII, Madrid, Consejo Superior de Investigaciones Científicas, 1966 (reed. en 1984), nota 30 de la pág. 555; y a partir de este último, por Victoriano GonZÁLEZ (OSB), El padre Feijoo y su monasterio de Samos, Lugo, Tipografía "La Voz de la Verdad", 1966 (Publicaciones de la Real Abadía de Samos, II), pág. 8, y por Ofelia Rey CAstelao, "El monasterio de Samos en la Edad Moderna. La sombra del padre Feijoo", en María del Carmen Folgar de la Calle y Ana Goy Diz (coords.), San Xulián de Samos: historia y arte en un monasterio. Opus Monasticorum III, Santiago de Compostela, Xunta de Galicia. Consellería de Innovación e Industria, 2008, pág. 89.

8 A. López Peláez, El monasterio de Samos..., pág. 139.
} 

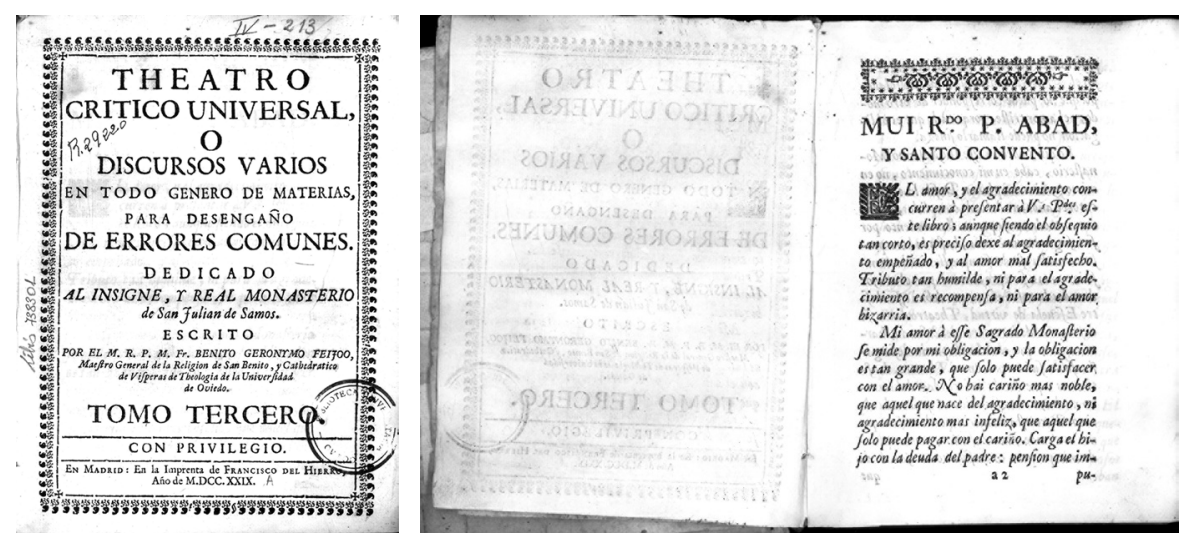

Portada y primera página de la «Dedicatoria» del tomo III del Theatro Crítico Universal (Madrid, 1729; primera edición). Biblioteca de la Universidad de Oviedo.

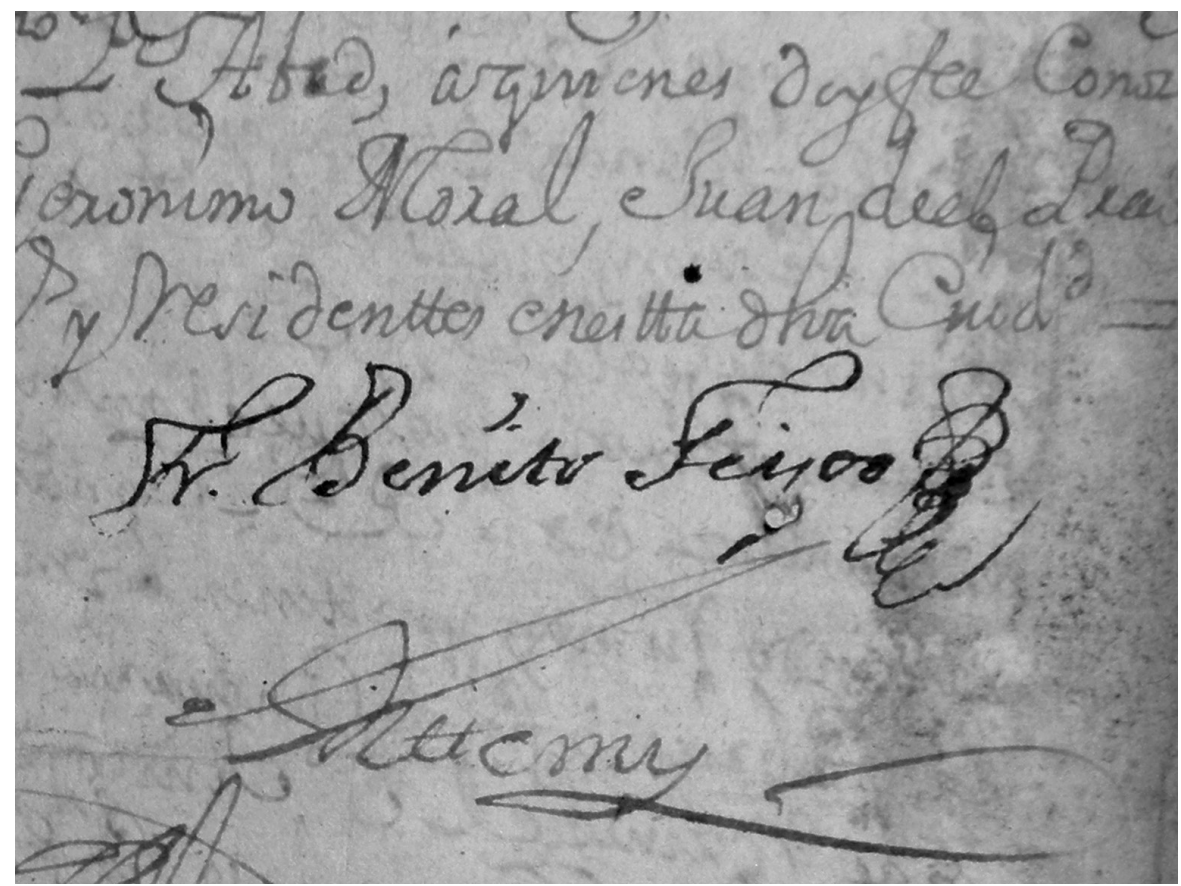

Firma del padre Feijoo al pie del documento de traspaso de los derechos de impresión de sus obras a favor del monasterio de Samos (Oviedo, 18 de septiembre de 1734). 
El producto de sus obras literarias (vendidas siempre con equidad, conforme à lo que prescribe San Benito) fue dividido entre Dios, y sus Pobres: lo que no entrò en el poder de estos, lo consagrò à Dios, sobre esse Altar, à cuyos pies postrado havia hecho el solemne sacrificio de su Professión. Considerando, que el antiguo Templo de este Monasterio caminaba à su ruina con los muchos siglos, que contaba, ha sido el Zorobabel, que con sus consejos, puso los cimientos de este Templo en que adoramos al Señor: Exhortò, y animó los Abades à esta obra, que excedìa las fuerzas de el Monasterio, $\mathrm{y}$ logrò sus deseos. Con el producto de sus fatigas es el Zorobabel, que ha de concluir la fabrica, y adornar los Altares. Para la conclusión de el Templo (impossible sin este socorro), para su adorno, para el Culto de Dios en el sitio, en que logrò ser admitido Religioso, para obsequio de los Santos, que invocò Testigos de su Profession, cediò los Privilegios que tenia para reimpression de sus Obras hace treinta años; sin que su producto pueda tener otro destino, dirigido por este Monasterio 9 .

Nóboa, que había profesado en Samos en 1730 y que fue su abad en dos ocasiones (1749-1753 y 1769-1773; murió en 1785) ${ }^{10}$, es veraz y concreto hasta en las fechas ("hace treinta años" fue, precisamente, en 1734), pues fue testigo y gestor de este rasgo de altruismo del padre Feijoo para con la casa de su profesión. Durante el abadiato de fray Eladio de Nóboa se construyeron además los retablos del transepto, a los que también se refiere de modo genérico en su Oración. Zorobabel, el personaje bíblico al que Nóboa parangona a Feijoo, era hijo de Saaltiel y fue quien ordenó la reconstrucción del segundo Templo de Jerusalén (consagrado el año 515 a. de C.; el primero había sido destruido por el rey caldeo Nabucodonosor II en el 586 a. de C.), después de la vuelta del pueblo de Israel de su cautiverio en Babilonia. El episodio está narrado en el libro de Esdras (Esd 3, 1 y sigs.) y el personaje figura también en los de Nehemías y Zacarías, ambos del Antiguo Testamento.

\footnotetext{
9 Oración fúnebre en las exequias, que en 22. de enero de 1765. celebrò el Real Monasterio de S. Julián

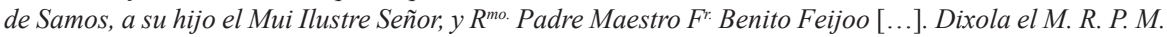
Fr. Heladio de Nóboa, Hijo, y Abad que ha sido de el mismo Monasterio, Maestro General, y Difinidor de la Religión de San Benito. Sácala a luz la Real Casa de Samos, Salamanca, Antonio Villargordo y Alcaràz, [s. a.: 1765], págs. 46-47 (hay otra ed.: Madrid, Manuel Martín, 1765, págs. 46-47). De Manuel Martín, inquieto impresor (que tenía su oficina en la madrileña calle de La Cruz) y activista de la edición popular, adaptada y económica de la obra de Feijoo, trata con detalle F. LOPEZ, "La obra de Feijoo en la historia de la edición española...”, págs. 332-336.

${ }^{10}$ E. Zaragoza i Pascual, "Libros de gradas de benedictinos...", pág. 874, y E. Zaragoza Pascual, “Abadologio del monasterio de Samos...”, págs. 493 y 494, núms. 111 y 116.
} 
Las Constituciones de la Congregación de San Benito (por la reforma de Valladolid) impedían a los monjes la posesión y disfrute de dinero y bienes de fortuna ${ }^{11}$. Así que el padre Feijoo, además de consagrarlos al "Altar, à cuyos pies postrado havia hecho el solemne sacrificio de su Professión", dispuso de sus pingües rentas para obras de caridad. Y ocasiones para ponerla en práctica no le faltaron durante la hambruna que padeció Asturias en 1741 y 1742, como recordaba el magistral de la catedral de Oviedo Alonso Francos Arango en la Oración fúnebre que por el alma de Feijoo se dijo en la Universidad de Oviedo el 27 de noviembre de $1764 .^{12}$

Esta contribución dineraria al monasterio de Samos también figura en las biografías decimonónicas del padre Feijoo, pero de un modo ambiguo y nada concluyente. José María Anchóriz, cuando trata los rasgos humanos de Feijoo, destaca el singular espíritu caritativo, acrecentado más si cabe por el rendimiento de sus obras: "Su inclinación dominante fue el estudio; su primera virtud, la caridad. Recibidos sus escritos con entusiasmo indecible, circularon por todos los puntos de la península, y por muchos del estranjero [sic], produciendo su venta cuantiosas sumas" ${ }^{13}$. Y añade que "después de su muerte el monasterio de Samos

\footnotetext{
${ }^{11}$ Constituciones de la Congregación de Nvestro Glorioso Padre San Benito de España, è Inglaterra. Avgmentadas, y añadidas con las nuevas Difiniciones, que desde el año de 1610. hasta el de 1701. han sido establecidas, y aprobadas en diversos Capitulos. Y el día de oy tienen ya fuerza de Leyes. Recopiladas, y redvcidas a mejor Methodo, y orden, por los Comissarios que la Santa Congregacion nombrò, y señalò para su Recopilacion, en su Capitulo General de 1701. Impressas en Madrid a costa de la Congregacion, En la Oficina de la Viuda de Melchor Alvarez, Año de 1706; véase el cap. XIv ("Pobreza monacal") del libro II ("Del govierno de los Monasterios"), págs. 196-199.

12 "Pero ya es tiempo que hablemos de la limosna,... Tan inclinado à la piedad ha sido siempre el Señor FEIJOO, que solo podia dejar de ser virtud, por serle, como lo era tan connatural; pues las puertas de su clemencia para con los pobres, siempre han estado francas, y patentes, y á estos, que eran sus mayores amigos, podia decir lo que San Pablo à los suyos:... pues se sabe por cosa cierta, è inconcusa, que jamas alguno le pidio limosna que se fuesse sin élla de su presencia. Sabese tambien, que en los años de 41. y 42. muy esteriles, y miserables en este Pais, empleò en granos grande suma de caudal, para que infinitos pobres tuviessen que comer, y para que les quedasse tambien para sembrar, para cuyo piadoso, y santo fin tenia empleadas varias personas, no solo en esta Ciudad, sinò en muchas Aldeas, y porque de noche por la clausura no podia salir á dar limosna, pero como los pobres ya le conocian, iban a clamar bajo de su Celda, y les arrojaba prontamente por las Ventanas embueltos en papeles reales, y pesetas: $\mathrm{Y}$ en medio que no se pudo hacer computo seguro, pero se creè, que llegò á muchos miles de ducados la limosna que dió, en los dos años referidos; $\mathrm{Y}$ como es muy ingenioso el amor, y los pobres eran todo su bien querer, haviendo escrupulizado poder expender tanto, aun de lo que ganava (como dicen) por su puños, y producía la abundante venta de sus libros, como el dominio de todo su haber, pertenecia á la Casa, en donde Professó, en medio de tener licencia suya, para distribuir en limosnas lo que quisiera, no obstânte para quietud de su conciencia delicada, pìdió, y obtuvo de su Santidad la licencia misma." (Alonso Francos Arango, Oración fúnebre, que en las solemnes exequias que la Universidad de Oviedo consagró en el día 27. de noviembre de este año de 1764. a la immortal memoria del Ilustrissimo, y Reverendissimo S. D. F. Benito Geronimo Feijoó y Montenegro, etc., Oviedo, Francisco Díaz Pedregal, 1765, págs. 23-25).

${ }^{13}$ José María ANCHóRIz, "Biografía y juicio de las obras que escribió el Ilustrísimo y Reverendísimo Padre Fray Benito Gerónimo Feijóo, del Consejo de S. M., Maestro General de la Orden de San Benito de la reforma de Valladolid", en Discurso leido en la solemne apertura de los estudios de la Universidad
} 
á quien, por ser el primitivo de Feijóo, volvieron todos sus bienes, percibió los productos de la venta de sus obras, y es fama que con ellos costeó el magnífico templo no inferior á algunas catedrales" ${ }^{\prime 14}$. Esto reproducen Vicente de la Fuente, tomado directamente de Anchóriz, y Gregorio Marañón, aunque con un deje de escepticismo, que, en cambio, lo hizo a partir de Francos Arango ${ }^{15}$.

Pero había sido mediado el siglo xix cuando se perdió el recuerdo de la efectiva contribución de Feijoo a las obras del monasterio de Samos. Y el primero en ponerla en duda fue nada menos que el prócer galleguista don Manuel Murguía ${ }^{16}$, y ya arrastró la opinión de otros publicistas, como Miguel Morayta que, en 1876 señalaba que "puede referirse tradicionalmente, que la conclusión de aquella suntuosa morada se sufragó con el producto de estos libros"17.

En cambio, fue el historiador samonense fray Plácido Arias quien, reflexionando sobre este rasgo de altruismo de Feijoo, trató de puntualizar la cuantía y extensión de su aportación a la construcción de la nueva iglesia de Samos a partir de 1734. Comienza su artículo así: "No es infrecuente oír que la Iglesia de Samos se levantó con el producto de los libros del P. Feijóo y que con el de la primera edición póstuma de los mismos se construyó la gran portada de tan suntuoso edificio"18. Pero fray Plácido creía más bien que la mayor parte de los recursos para esta empresa provinieron de las rentas del propio monasterio, del producto de

Literaria de Oviedo el día $1 .^{\circ}$ de octubre de 1857, Oviedo, Imprenta y Litografía de Brid, Regadera y Comp., 1857, pág. 6. A este rasgo limosnero (“el genio, no la virtud, me arrastra azia eso") alude el propio Feijoo en una carta al padre Sarmiento, fechada en Oviedo, el 31 de mayo de 1738 (ápud Maximino ArIAS Cuenllas, "Catorce cartas de Feijoo al P. Sarmiento", Boletín del Centro de Estudios del Siglos XVIII, núms. 4-5 [1977], págs. 13-14, y núm. 5, págs. 31-35).

${ }^{14}$ J. M. a AnChóRIz, "Biografía y juicio de las obras...", pág. 7. En realidad, no se trataba de un acto de altruismo o cariño: las Constituciones de la Congregación de Valladolid (citadas supra, nota 11) establecían que a la muerte de un monje, "todas las alhajas, libros, quadros, dinero, y todo lo que qualquier Religioso, de qualquiera condicion que sea, tuviere, y en su muerte se hallare, pertenecen, y con efecto deben ser de la Casa de su profession, sin que aquella de que es Conventual pueda aver cosa alguna, etc."; y la de Feijoo fue, como va dicho, San Julián de Samos. Véase § 6, cap. XIII ("Expolio de difvntos, y su inventario, y repartimiento") del libro II de las Constituciones de la Congregación de Nvestro Glorioso Padre San Benito de España, è Inglaterra..., pág. 193.

15 V. de la Fuente, "Preliminares", pág. Xix. Gregorio Marañón, Las ideas biológicas del padre Feijóo, Madrid, Espasa-Calpe, S. A., 1941, 2. ${ }^{\text {a }}$ ed. (1. ${ }^{\text {a }}$ ed.: Madrid, 1934), pág. 15, nota 3: "Se dice en muchos de los escritos feijonianos que el importe de la venta de los libros del benedictino fué tan grande que con él se construyó la magnífica iglesia nueva del monasterio de Samos, etc.".

${ }^{16}$ Manuel Murguía, Diccionario de escritores gallegos, Vigo, J. Compañel, Editor, MDCcClXII [1862], pág. 201, nota 1. La aportación del patriarca de las letras gallegas al estudio de la vida y obra de Feijoo es reseñada por R. Otero Pedrayo, El padre Feijoo..., págs. 741-742.

17 Miguel Morayta Sagrario, "El Padre Feyjoó", La Ilustración Española y Americana, año XX, núm. XXXVII (1876), Madrid, 8 de octubre, pág. 207c.

18 Plácido Arias y Arias (OSB), "El P. Feijóo y la Iglesia de Samos”, Boletín de la Comisión Provincial de Monumentos Históricos y Artísticos de Lugo, t. II, núms. 14-15 (1945), pág. 51; y también en P. ArIAs, Historia del Real Monasterio de Samos, pág. 265. 
una de sus mejores granjerías, las ferrerías, ya que (sigue diciendo), según consta y acreditan sus contemporáneos, Feijoo fue muy pródigo en gastar sus ingresos socorriendo a los necesitados ${ }^{19}$. Y en fe de ello, comenta las referencias que a esto se leen en las oraciones fúnebres que al Padre Maestro dedicaron Francos Arango y fray Eladio de Nóboa $^{20}$, ya recordadas. Y para lo referido al producto de la primera edición conjunta y póstuma de sus Obras, recuerda el padre Arias que las dos primeras se hicieron a expensas de la Compañía de Impresores y Libreros, no del monasterio de Samos, que solo se pudo hacer cargo de ella en 1781, en la que fue la quinta edición de las conjuntas, cuando, aduce, ya estaban concluidos el templo y su monumental fachada. O sea, el mismo razonamiento que Manuel Murguía había hecho en $1862 .{ }^{21}$ Los ingresos de esta quinta edición, sigue diciendo el padre Arias, sirvieron, en cambio, para financiar la obra del retablo de la capilla mayor (y sacristía, dice también ${ }^{22}$.

Otero Pedrayo igualmente abordó este asunto. Afirmaba que el padre Feijoo fue "uno de los primeros escritores de que consta haya obtenido dineros considerables" (y apostilla que "el dinero de origen literario siempre causó estupefacción en España"), y lo mucho que ganó fue "para los pobres y para Samos". Pero, recogiendo lo argumentado por Nóboa y Anchóriz, y siguiendo a los padres Plácido Arias y Victoriano González, refiere que la fachada de la iglesia de Samos estaba concluida en 1748 y que la edición conjunta de las obras de Feijoo hecha por el monasterio de Samos en 1781 sirvió para financiar el retablo mayor y la rotonda de la sacristía ${ }^{23}$.

Visto retrospectivamente, acaso lo más rico e interesante de la herencia del Padre Maestro al monasterio de Samos (aparte del privilegio de edición de sus obras completas a partir de 1781) ${ }^{24}$ haya sido el insufructo de su biblioteca

\footnotetext{
${ }_{19}$ Esta idea también la asumió su sobrino, el padre M. Arias CuEnllas, "Catorce cartas de Feijoo al P. Sarmiento", págs. 19-20. En efecto, las ferrerías fueron una de las fuentes de ingresos más saneadas y constantes del monasterio samonense, como documentó O. Rey Castelao, "El monasterio de Samos en la Edad Moderna...", págs. 82-83.

20 A. Francos Arango, Oración fúnebre..., págs. 24-25; H. NóBOA, Oración fúnebre en las exequias..., págs. 46-47; P. Arias, “El P. Feijóo y la Iglesia de Samos”, págs. 51-52.

21 Esta contradicción también la advirtió Murguía, porque cuando en 1781 se hizo la edición de las Obras completas de Feijoo por el monasterio de Samos, la iglesia llevaba varios años acabada (M. Murguía, Diccionario de escritores gallegos, pág. 201, nota 1). Y se hace eco de ella ("es una leyenda que desmiente Murguía”) G. Marañón, Las ideas biológicas del padre Feijóo, pág. 15, nota 3.

${ }^{22}$ P. Arias, "El P. Feijóo y la Iglesia de Samos", pág. 53. A este respecto, señala Ofelia Rey que en Samos, "entre 1781 y 1785 , se invirtieron en obras y reparaciones 254.744 reales, la partida más voluminosa con diferencia; 53.525 reales sumaron los gastos de sacristía..." (O. Rey CAStelao, "El monasterio de Samos en la Edad Moderna...", pág. 83).

23 R. Otero Pedrayo, El padre Feijoo ..., pág. 297.

${ }^{24}$ Véase la "Nota" editorial al t. I del Theatro Crítico Universal. Nueva edición corregida y aumentada, Madrid, Blas Román, MDCCLXxxi [1781], págs. XXVI-XXVII. En vida del Maestro Feijoo, sus libros se iban editando a medida que se sucedía su redacción y se reimprimían cuando se agotaban, con mucha "impericia
} 
particular ${ }^{25}$. Con la Desamortización (1835), la Diputación Provincial de Lugo se incautó de la de Samos, pasando sus volúmenes a engrosar la Biblioteca Pública Provincial ${ }^{26}$. En ella, junto a los libros que fueron de Feijoo (se estiman unos seiscientos títulos, al margen de sus papeles manuscritos y trabajos inéditos), estaban los de otros señalados hermanos de religión, como los del obispo de Jaca y Mondoñedo, fray Antonio Alejandro Sarmiento de Sotomayor (1683-1751), hijo y antiguo abad de Samos (1717-1721), y Maestro General de la Congregación (1721-1725) $)^{27}$. A este respecto, conviene recordar que Antonio Sarmiento fue censor del primer tomo del Theatro Crítico Universal y destinatario de la dedicatoria del segundo (1726 y 1728) ${ }^{28}$. El 30 de agosto de 1941, a instancias del abad de Samos, fray Mauro Gómez Pereira, la Diputación de Lugo acordó depositar los

\footnotetext{
y descuido" por parte de la Orden, en opinión de F. LoPEz, "La obra de Feijoo en la historia de la edición española...", págs. 326-327. A partir de 1764, se siguieron publicando pero de manera conjunta, bajo la fórmula de Obras completas. Por privilegio del Consejo de Castilla, las cuatro primeras colecciones fueron editadas por la Compañía de Impresores y Libreros del Reino (Madrid, 1765, 1769-1770, 1773-1774 y 1777-1778) y solo la quinta (Madrid, 1781) lo fue a cargo del monasterio de Samos, heredero legal de todos los bienes, acciones y derechos del padre Feijoo, como hijo de esta casa. La historia de las ediciones de las obras de Feijoo la traen J. M. CASO y S. Cerra, Benito Jerónimo Feijoo. Bibliografia ..., núms. 367, 370,373 , 377 y 382 , págs. $195-198,200-201,204-205,208-210$ y 213-215, respectivamente.

25 "Los libros se pondràn en la librería de la Casa de su profession, por que à ella pertenecen, sino los huviere en dicha librería: y si los huviere, se venderàn para comprar otros que en la libreria faltaren, ò se repartiràn entre los Monges." (§ 7, cap. XIII, "Expolio de difvntos, y su inventario, y repartimiento", del libro II de las Constituciones de la Congregación de Nvestro Glorioso Padre San Benito de España, è Inglaterra ..., pág. 193). Para la librería del padre Feijoo, véase Agustín Hevia Ballina, "Hacia una reconstrucción de la librería particular del P. Feijoo", Studium Ovetense, 4 (1976), págs. 139-186; Agustín Hevia Ballina, "Un nuevo acercamiento al Padre Feijoo: el catálogo de la librería del monasterio de San Vicente de Oviedo", Studium Ovetense, 8 (1980), págs. 311-346; Agustín Hevia Ballina, "El Padre Feijoo, hombre de la Ilustración: sus aficiones histórico-geográficas", Studium Ovetense, 9 (1981), págs. 29-57; Agustín Hevia Ballina, "La biblioteca clásica del P. Feijoo", en II Simposio sobre el Padre Feijoo y su siglo (ponencias y comunicaciones), vol. 1, Oviedo, Centro de Estudios del Siglo XVIII, 1981, págs. 375392, y Agustín Hevia Baldina, "Libros de medicina en la librería particular del Padre Feijoo", Studium Ovetense, 10 (1982), págs. 31-46.

${ }^{26}$ [Francisco Javier Pardo y José Millán], Catálogo de las obras existentes en la Biblioteca Pública Provincial. Con una introducción del Dr. D. Germán Alonso Hortas, Lugo, Diputación Provincial de Lugo, 1935, "Introducción", págs. v-VI, e "Índice especial de las obras pertenecientes a la 'librería particular' del Padre Maestro Fr. Benito Feyjoo existentes en esta Biblioteca Pública Provincial”, págs. 189-190 (son 71 entradas). Debo la consulta de este impreso a la amistad del señor don Emilio Marcos Vallaure.

${ }^{27}$ Ernesto Zaragoza Pascual, "Un abadologio inédito de Samos, del siglo XVIII", Stvdia Monástica, XXII/2 (1980), págs. 339-340, núm. 99 (edición de un ms. de 1736, debido a fray Antonio Benito de Rivera, archivero de Samos y posteriormente su abad [1733-1737], conservado en el Archivo del Monasterio de Santo Domingo de Silos, Burgos); E. Zaragoza Pascual, "Abadologio del monasterio de Samos...", pág. 491, núm. 103.

${ }^{28}$ Sarmiento de Sotomayor adquirió "600 volúmenes para la biblioteca de Samos" (E. ZARAGOZA PASCUAL, "Un abadologio inédito de Samos...", págs. 339-340, nota 117, núm. 99). Para la amistad intelectual de Feijoo con fray Antonio Sarmiento de Sotomayor, véase asimismo, Narciso Pérez, "La celda del P. Feijoo en Samos", Monásticon. Revista de información benedictina, II (1935), págs. 143-154 (que cito por la reedición hecha por V. GonzÁlez, El padre Feijoo y su monasterio de Samos, Apéndice II, págs. 24-25, y nota 5, págs. 28-30).
} 
fondos de la biblioteca feijooniana (por entonces, ya contaba solo setenta y seis títulos) en el monasterio de Samos, de donde provenían, lo que se llevó a efecto el 4 de octubre de aquel año. Pero todo este legado se perdió con el incendio del monasterio, el 24 de septiembre de 1951. Así que de la biblioteca que fue de Feijoo solo restan unas pocas muestras, un puñado de cartas y los libros eclesiásticos reunidos en el siglo XIX para formar la biblioteca del Seminario Diocesano de Lugo, cuya sede actual data de $1893 .{ }^{29}$

\section{El Retrato del PADRE FeiJoO Y LA CESIÓN DE DERECHOS DE EDICIÓN: ¿CASUALIDAD O CORRESPONDENCIA?}

El año 1733-1734, cuando el padre Feijoo contaba cincuenta y siete años, fue el mismo en que el pintor Francisco Martínez Bustamante (Santander, 1680-Oviedo, 1745) hizo su retrato en Oviedo y en el que Juan Bernabé Palomino (Córdoba, 1692-Madrid, 1777) lo grabó en Madrid para estampar y poner al frente de sus obras ${ }^{30}$. Ese momento, realmente, coincidió con la edición del tomo VI del Theatro Crítico Universal (Madrid, 1734) y por tanto, el retrato se pudo incluir como novedad en la anteportada de algunos ejemplares de esa nueva entrega, aunque la estampa también se vendía suelta ${ }^{31}$. Este retrato fue la vera effigies del

\footnotetext{
29 P. ARIas, Historia del Real Monasterio de Samos, págs. 410-411; V. GonZÁLEz, El padre Feijoo y su monasterio de Samos, págs. 7-8, y N. PÉrez, "La celda del P. Feijoo en Samos”, pág. 24 (ápud V. GonzÁlEz...). M. Arias Cuenllas, Historia del monasterio de San Julián de Samos, págs. 318 y 489-490. A la biblioteca de Feijoo conservada en Samos también se refiere en varios lugares G. MARAÑón, Ideas biológicas del padre Feijóo, págs. 109, nota, 218, nota, y pássim.

${ }^{30}$ Bustamante figura avecindado en Oviedo desde 1699, pero completó su formación en Madrid, con el pintor asturiano Miguel Jacinto Meléndez (Oviedo, 1679-Madrid, 1734), como indicó Juan Agustín CEÁN Bermúdez (Diccionario histórico de los más ilustres profesores de las Bellas Artes en España, Madrid, Imprenta de la Viuda de Ibarra, 1800, t. I, pág. 183). Trabajó para la catedral de Oviedo, órdenes religiosas y la principal nobleza asturiana y santanderina, siendo muy valorado como retratista. Bustamante fue estudiado en nuestra tesis doctoral, Actividades pictóricas en Asturias en la Época Moderna. La pintura del siglo XVIII (Universidad de Oviedo, 1990; inédita). Véase Javier GonzÁlez SAnTos, "Martínez Bustamante, Francisco Antonio", en Apéndice de la Gran Enciclopedia Asturiana (1981-1991), t. XX, Gijón, Silverio Cañada Ed., 1996, págs. 10-12. Por formación, estilo y géneros cultivados, Martínez Bustamante es parangonable con otros pintores contemporáneos de la periferia peninsular, como el gallego Juan Antonio García de Bouzas (ante 1680-1755) o el catalán Antonio Viladomat (1678-1755). Juan Bernabé Palomino era sobrino y discípulo de Antonio Acisclo Palomino de Castro y Velasco, pintor, tratadista y biógrafo de los artistas españoles. Fue el primer grabador de cámara de los Borbones, a cuyo servicio entró a trabajar en 1719, aunque el título efectivo data de 29 de noviembre de 1736. Fue, asimismo, director de grabado en la Academia de Bellas Artes de San Fernando desde su fundación en 1752, donde formó a toda la generación de grabadores de la Ilustración española (J. A. CEÁN BERMúdEZ, Diccionario histórico..., t. IV, págs. 27-29, y Juan CArrete Parrondo, El grabado calcográfico en la España Ilustrada, Madrid, Club Orbis, 1978, págs. $22 b c$ y pássim).

31 Javier GonzÁlez SAntos, "Iconografía dieciochista del padre Feijoo. Un estudio del mercado editorial y su incidencia en la difusión de la imagen del sabio benedictino", en Inmaculada Urzainqui (ed.), Feijoo, hoy. Semana Marañón 2000, Oviedo, Fundación Gregorio Marañón - Instituto Feijoo de Estudios del Siglo XVIII, 2003, págs. 162-169, figs. 1, 2 y 6.
} 
monje, siendo copiada por Joaquín Ballester (Valencia, 1740-Madrid, 1808) para ilustrar la edición del primer tomo de las Obras completas publicadas por la Real Compañía de Impresores y Libreros (Madrid, 1765), mientras la lámina original de Palomino de 1734, retallada por Juan Moreno Tejada (Carrión de los Condes, Palencia, 1736-Madrid, 1805) en 1781, lo fue para la de la edición conjunta de Samos (Madrid, Blas Román, 1781, en 14 tomos) ${ }^{32}$.

Atendiendo a la fecha (1734), ¿no estarán ligados ambos acontecimientos: la cesión de derechos de edición y la hechura del retrato de Feijoo? A mayor abundamiento, en Samos, en la celda prioral del claustro gótico, hay un retrato suyo, por el mismo modelo del de Bustamante y Palomino de 1734 (óleo sobre lienzo, $80 \times 61 \mathrm{~cm})$. Fue recuperado en 2008 pues, desde la Desamortización era propiedad de la Diputación de Lugo; pero no sé si estuvo en el Museo Provincial o en la sede de la propia Diputación. Tiene esta inscripción, abajo: "JLL. ${ }^{\text {mus }} \mathrm{R}^{\mathrm{mus}}$ P. M. F. Benedictus Hieronymus Feijoò", parecida a la que figura en la estampa de Palomino. Se tratará, al parecer, del mismo que en el Inventario de la Desamortización, verificado en Samos, el 28 de abril de 1836, aparece asentado en la celda abacial: "Otros tres [cuadros] que representan a Fray Antonio Sarmiento, Fray Cristóbal Areste [sic: Aresti] y al famoso de Fray Benito Feijó" 33 . Aunque repintado y rehecho del todo, aparte de reentelado, se podría tratar de una réplica del original de Martínez Bustamante de 1733-1734 (cuyo original se encuentra perdido), solicitada por Samos a Oviedo con motivo del dadivoso gesto de Feijoo para con la casa de su profesión ${ }^{34}$.

\section{El templo de San Julián y otros Recintos monásticos de Samos}

La iglesia vieja de Samos aun estaba en obras por el año $1228:{ }^{35}$ pero para cuando se decidió construir la actual, el primitivo templo medieval ya había

\footnotetext{
32 J. GonZÁlez SAntos, "Iconografía dieciochista del padre Feijoo...”, págs. 169-173, figs. 7-10.

33 Archivo Histórico Provincial de Lugo: Desamortización, sign. 18.470 (información consultada por la transcripción que figura en el disco compacto [CD] que incluye la edición de María del Carmen Folgar de la Calle y Ana Goy Diz [coords.], San Xulián de Samos: Historia y arte en un monasterio. Opus monasticorum III, Santiago de Compostela, Xunta de Galicia, 2008, carpeta: Inventario III ok.doc).

${ }^{34}$ En el monasterio de Samos, en la llamada celda de Feijoo (en el claustro grande), hay otro retrato suyo pintado (lienzo, 88,9 × 69,8 cm), pero es una de las muchas copias generadas a partir del grabado de Palomino de 1734, tanto en la segunda mitad del siglo XVIII como en el XIX (véase J. GonZÁLEZ SANTOS, "Iconografía dieciochista del padre Feijoo..."). Acaso se trata de una muestra traída al monasterio por algún celoso monje a partir de 1880, cuando se restauró la vida religiosa en Samos. Se puede ver reproducido en M. Arias Cuenllas, Historia del monasterio de San Julián de Samos, fig. 6, frente a la pág. 303, y (aunque en miniatura) en Pedro de la Portilla (OSB), San Julián de Samos: monasterio benedictino, León, Edilesa, 1993, pág. 30.

35 Para la fábrica de este templo medieval, que quizás comenzara alrededor de 1167, véase Estefanía LóPEZ SALAS, "Propuesta metodológica para la restitución de la planimetría de una arquitectura medieval desapa-
} 


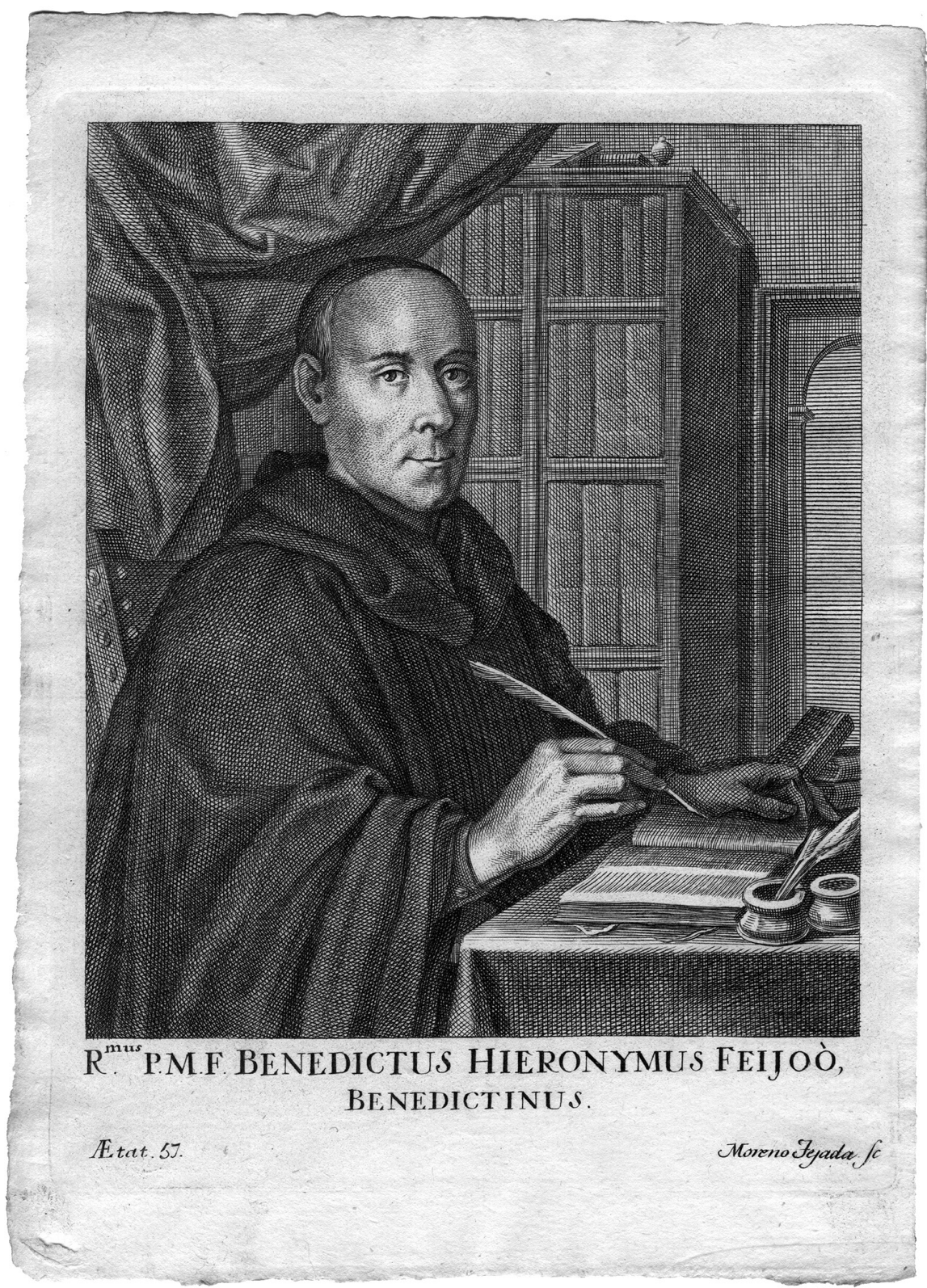

Juan Bernabé Palomino (1692-1777) y Juan Moreno Tejada (1736-1805), grabador, El padre Feijoo, 1781; cobre, talla dulce; lámina, $191 \times 147 \mathrm{~mm}$ (papel, $220 \times 158 \mathrm{~mm}$ ). Retallada sobre la lámina original de 1733-1734. Colección del autor. 
sido reconstruido y reformadas su capilla mayor (1606-ante 1613) y la sacristía (1610-1613). Esta campaña de renovación continuó con la labra del retablo mayor (1613-1617) y de otros cuatro laterales (1618-1621) por el escultor Francisco Moure (Santiago, 1576-Monforte de Lemos, 1636) ${ }^{36}$; de la cajonería de la sacristía (1613-1617), rejas del coro, púlpitos y órgano (1621-1625), y concluyó con la fábrica del cimborrio o media naranja del crucero de la iglesia en 1633-1637. Ello aconteció durante los abadiatos de fray Francisco del Castillo (1604-1607 y 1610-1613; muerto hacia 1623) ${ }^{37}$, fray Cristóbal de Aresti (1613-1617 y 1621 1625; muerto en 1638) ${ }^{38}$, fray Miguel Sánchez (1618-1621 y 1625-1629) ${ }^{39}$ y fray Mauro de Vega (1633-1637 y 1641-1645; muerto en 1659) ${ }^{40}$.

Por otro lado, el llamado claustro gótico se comenzó a erigir en 1562; en él intervino el cantero Pedro Rodríguez de Remberde (muerto en Sarria, Lugo, hacia 1591), vecino de Monforte de Lemos, que fue quien cerró el cuerpo bajo en 1582, por el último tramo meridional de la crujía occidental; la solería se echó

recida: la iglesia románica del monasterio de San Julián de Samos (Lugo)", Arqueología de la Arquitectura, 10 (2013), págs. 1-19. Referencias clásicas son las de Juan Agustín CEÁN BERmúDEZ, “Adiciones" a las Noticias de los arquitectos y arquitectura de España desde su Restauración, por el Excmo. Señor D. Eugenio Llaguno y Amírola, ilustradas y acrecentadas con notas, adiciones y documentos por D. Juan Agustín Ceán-Bermúdez, Madrid, Imprenta Real, 1829, t. I, pág. 51. El dato (aunque Ceán no lo hace explícito) está tomado de fray Manuel Risco (OSA), España Sagrada. Tomo XLI. De la Santa Iglesia de Lugo: Continuación de su historia desde el siglo XII. hasta fines del XVIII. Etc., Madrid, Oficina de la Viuda é Hijo de Marín, MDCCXCVII [1798], págs. 60-61, y Apéndice XXXI, págs. 359-361. Y Manuel CASTRO, "Un monasterio gallego", Boletín de la Comisión Provincial de Monumentos Históricos y Artísticos de Orense, t. IV, núm. 82 (1912), págs. 114-115.

${ }^{36}$ Marica LóPez CADERón, "La obra del «escultor y arquitecto» Francisco de Moure en San Xulián de Samos”, en María del Carmen Folgar de la Calle y Ana Goy Diz (coords.), San Xulián de Samos: historia y arte en un monasterio. Opus Monasticorum III, Santiago de Compostela, Xunta de Galicia. Consellería de Innovación e Industria, 2008, págs. 193-208.

37 E. Zaragoza Pascual, "Un abadologio inédito de Samos...", pág. 330, núms. 66 y 68; M. Arias CuenLlas, Historia del monasterio de San Julián de Samos, págs. 220-221; E. Zaragoza Pascual, “Abadologio del monasterio de Samos...", pág. 483, núms. 70 y 72.

38 E. Zaragoza Pascual, "Un abadologio inédito de Samos...", págs. 331 y 332, núms. 69 y 72; E. ZARagoza Pascual, “Abadologio del monasterio de Samos...”, págs. 484 y 485, núms. 73 y 76.

39 E. Zaragoza Pascual, "Un abadologio inédito de Samos...", págs. 331 y 332, núms. 71 y 73; E. ZARagoza Pascual, “Abadologio del monasterio de Samos...”, págs. 484 y 485, núms. 75 y 77.

${ }^{40}$ M. CAstro, "Un monasterio gallego”, págs. 115-117. Miguel Durán, La Real Abadía de San Julián de Samos. Estudio Histórico-Arqueológico, Madrid, Blass, S. A., 1947, pág. 18. A. Bonet CorreA, La arquitectura en Galicia ..., pág. 555. Maximino Arias Cuenllas (OSB), Un abadologio inédito del monasterio de Samos [hacia 1722-1724]. Presentación, transcripción y notas por el P. Maximino Arias, Samos, Monasterio de Samos, 1968 (Publicaciones de la Real Abadía de Samos, IV), págs. 61, 62 y 63. E. ZARAGOZA Pascual, "Un abadologio inédito de Samos...", págs. 332-333, núms. 75 y 77; E. Zaragoza Pascual, “Abadologio del monasterio de Samos...", pág. 485, núms. 79 y 81. Ana E. Goy Diz, "La formulación de la arquitectura benedictina tras la incorporación a la Congregación. El monasterio de Xulián de Samos", en María del Carmen Folgar de la Calle y Ana Goy Diz (coords.), San Xulián de Samos: historia y arte en un monasterio. Opus Monasticorum III, Santiago de Compostela, Xunta de Galicia. Consellería de Innovación e Industria, 2008, págs. 141-145. 


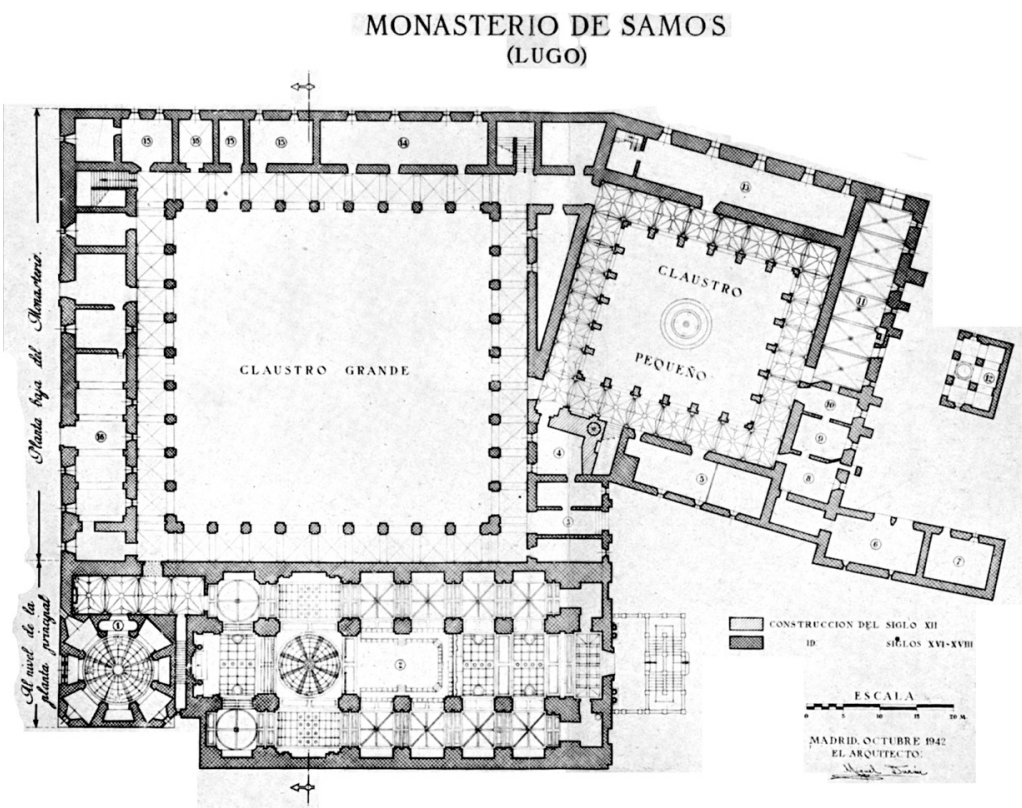

Planta del monasterio de Samos (octubre de 1942), por el arquitecto Miguel Durán; publicada en La Real Abadía de San Julián de Samos, Madrid, 1947.

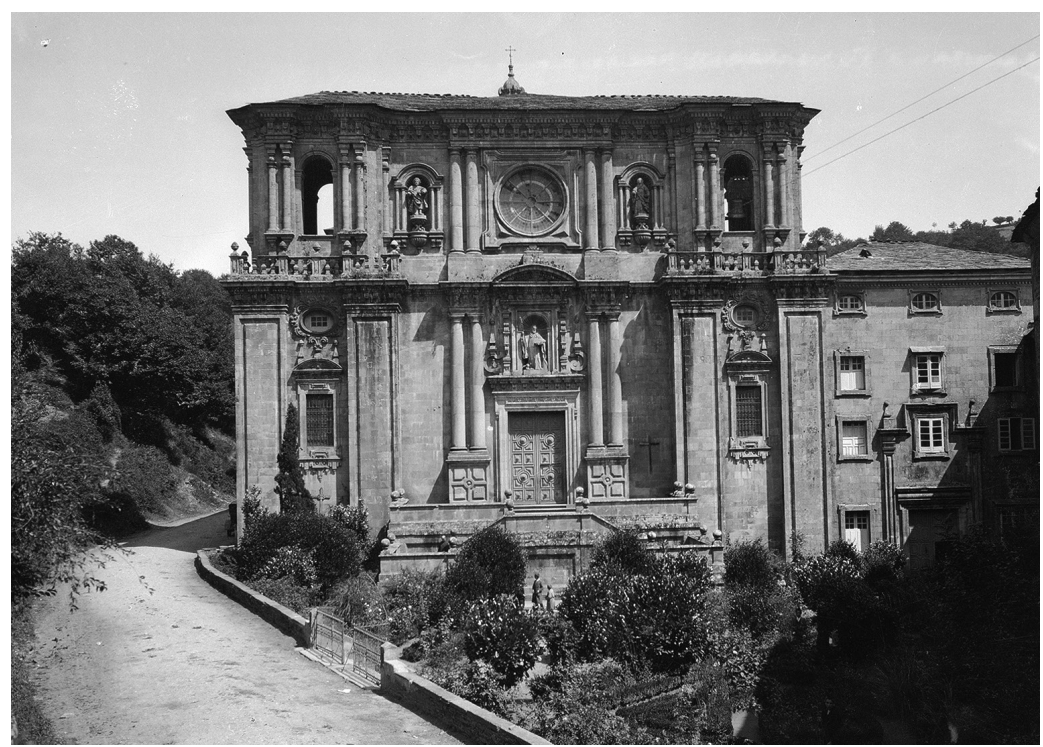

Fachada del monasterio de San Julián de Samos (hacia 1930-1945). Archivo Ruiz Vernacci (Vn-38622). Madrid, Fototeca del Instituto del Patrimonio Cultural de España (Ministerio de Educación, Cultura y Deporte). 
en $1592 .{ }^{41}$ Las obras se emprendieron tras el incendio de 1538, que en tiempos del abad fray Lope de la Barrera o Barreira (1525 hasta 1553; muerto en 1563) había arruinado el monasterio ${ }^{42}$. Luego, en 8 de septiembre de 1552, hubo otro que destruyó el archivo ${ }^{43}$. Por último, en 1633-1637, durante el abadiato de fray Mauro de la Vega, consta que se levantó un piso en dos de las crujías de este claustro ${ }^{44}$.

Pero la idea de renovar y ampliar esta casa, pues el antiguo monasterio ya se había quedado corto, es de $1685 .{ }^{45}$ La edificación del nuevo templo se hizo en un solar diferente del antiguo, pero aledaño, lo que permitió seguir usando la iglesia medieval mientras se construía la nueva y, como el tiempo vino a demostrar, acometer los trabajos con tranquilidad ${ }^{46}$. En esta empresa estuvieron comprometidos varios abades: los primeros fueron fray José Laguna (que lo fue en cuatro ocasiones: $1685-1689 ; 1693-1697$; 1697-1701 y 1713, pero renunció por enfermedad; murió en 1714) ${ }^{47}$, fray Anselmo de la Peña (en 1689-1693; muerto en 1729), que no dejó de interesarse por ellas siendo General de la Congregación (1697-1701) ${ }^{48}$, fray José Lozano (1709-1713; muerto en 1727) ${ }^{49}$ y fray Pedro Vea (1713-1717 y 1721-1725; muerto en 1733 $)^{50}$. Sus desvelos se centraron en la implantación y construcción de la cabecera y transepto de la nueva iglesia, sacristía y statio (o pasaje de esta al templo, al tiempo que corredor de comunicación con el claus-

\footnotetext{
$\overline{41}$ M. CAstro, “Un monasterio gallego", págs. 118-120. A. E. Goy Diz, "La formulación de la arquitectura benedictina...", págs. 134-138. Esta investigadora no cree que Pedro Rodríguez fuera en realidad el arquitecto, sino más bien un oficial; pero ¿qué oficial firmaría una obra, prerrogativa reservada solo a los tracistas y maestros? Además, de Pedro Rodríguez se sabe que trabajó para el conde de Lemos y que hizo el puente de Monforte.

${ }^{42}$ M. CAstro, "Un monasterio gallego”, págs. 117-118. M. Durán, La Real Abadía de Samos ..., págs. 17-18 y 54-55. M. Arias Cuenllas, Un abadologio inédito del monasterio de Samos, págs. 58-59. E. Zaragoza Pascual, "Abadologio del monasterio de Samos...", pág. 479, núm. 51.

${ }^{43}$ E. Zaragoza Pascual, "Un abadologio inédito de Samos...", págs. 326-327, nota 73, núm. 51; E. Zaragoza Pascual, “Abadologio del monasterio de Samos...”, pág. 479, núm. 51.

44 A. E. Goy Diz, "La formulación de la arquitectura benedictina...”, pág. 139.

${ }^{45}$ Las etapas y vicisitudes de la construcción del nuevo monasterio fueron esclarecidas por María del Carmen Folgar. Los párrafos que siguen son un resumen de su estudio de 2003, al que remitimos para mayores detalles, valoración de lo realizado y revisión del aparato crítico (María del Carmen FoLGAR DE LA CAlle, "La iglesia del monasterio de San Julián de Samos: fray Pedro Martínez y fray Juan Vázquez", en María del Carmen Folgar de la Calle, Ana Goy Diz y José Manuel B. López Vázquez [coords.], Memoria artis. Studia in memoriam M. ${ }^{a}$ Dolores Vila Jato, Santiago de Compostela, Xunta de Galicia, 2003, t. I, págs. 289-309).

46 M. a del C. Folgar de la Calle, "La iglesia del monasterio de Samos...", págs. 289 y $290 b$.

47 E. Zaragoza Pascual, "Un abadologio inédito de Samos...", págs. 337 y 338, núms. 91, 93 y 94; E. Zaragoza Pascual, “Abadologio del monasterio de Samos...”, págs. 489 y 490, núms. 95, 97 y 101.

${ }^{48}$ E. Zaragoza Pascual, "Un abadologio inédito de Samos...”, págs. 337-338, núm. 92; E. Zaragoza Pascual, “Abadologio del monasterio de Samos...”, pág. 489, núm. 95.

${ }^{49}$ M. Arias Cuenllas, Un abadologio inédito del monasterio de Samos, págs. 66-67. E. Zaragoza PasCuAL, "Un abadologio inédito de Samos...", pág. 339, núm. 97; E. Zaragoza Pascual, "Abadologio del monasterio de Samos...”, pág. 490, núm. 100.

${ }^{50}$ E. Zaragoza Pascual, "Un abadologio inédito de Samos...”, págs. 339 y 340, núms. 98 y 100;

E. Zaragoza Pascual, “Abadologio del monasterio de Samos...”, págs. 490-491, núms. 102 y 104.
} 
tro), erección de tres crujías del nuevo claustro (1693-1701) y en alguna reforma del claustro principal o gótico (1709-1713), refectorio (1694) e instalación de la fuente de las Nereidas (o de la Escalera, como originalmente se llamó) ${ }^{51}$, llegando hasta 1710-1712, aproximadamente, momento en que los trabajos de la iglesia fueron interrumpidos ${ }^{52}$.

El plan para la nueva iglesia, como documentaron Zaragoza Pascual ${ }^{53}$ y Folgar de la Calle, fue del arquitecto burgalés Pedro Martínez (en el siglo, Juan Martínez [Quintanilla de la Mata, Lerma, Burgos, 1675-monasterio de San Salvador de Oña, Burgos, 1733]) $)^{54}$. Esta última lo estima de hacia 1693-1698, por consiguiente, anterior a su ingreso como lego en la orden benedictina, siendo ya por entonces un conocido arquitecto; la profesión de fray Pedro se verificó en el monasterio de San Pedro de Cardeña (Burgos), el 8 de diciembre de $1698 .{ }^{55}$ Para Folgar de la Calle, la iglesia de Samos es, por lo tanto, la primera obra conocida y relevante del catálogo de fray Pedro, realizada cuando contaba entre 18 y 23 años, poco más o menos $^{56}$. Pero, a mi entender, acaso sea una data muy temprana y lo más prudente

\footnotetext{
${ }_{51}$ M. CAstro, "Un monasterio gallego", págs. 136 y 142. E. Zaragoza Pascual, "Un abadologio inédito de Samos...", pág. 339, núm. 98, nota 115; E. Zaragoza PAScual, "Abadologio del monasterio de Samos...", págs. 490-491, núms. 102 y 104. María del Carmen Folgar DE LA CALLE, "Iter operis o la relación sobre la definición de la fábrica del monasterio samonense: la construcción de la nueva iglesia y de un nuevo claustro", en María del Carmen Folgar de la Calle y Ana Goy Diz (coords.), San Xulián de Samos: historia y arte en un monasterio. Opus Monasticorum III, Santiago de Compostela, Xunta de Galicia. Consellería de Innovación e Industria, 2008, pág. 163, y nota 69, pág. 177.

${ }^{52}$ M. a del C. Folgar de la Calle, "La iglesia del monasterio de Samos...”, págs. 293b-294a.

53 Aunque creyó que estas obras, acometidas durante el segundo y tercer mandato del abad fray José Laguna (1693-1697 y 1697-1701), fueron seguidas "en la iglesia antigua", pues la actual la fecha en 17341748; véase Ernesto Zaragoza Pascual, "Visitas de los Generales de Valladolid al monasterio de Samos (1698-1832)", Yermo. Cuadernos de historia y de espiritualidad monásticas, vol. 20, núms. 1-2 (1982), págs. 46-47, nota 17. "Durante el segundo mandato [de fray José Laguna (1693-1701)] hizo obras en la iglesia antigua, con la capilla mayor y el crucero, que en la visita de 1698 se manda continuar, todo según traza del lego de Cardeña, Fr. Pedro Martínez, y además «hizo hasta el tercer paño del claustro nuevo»" (E. Zaragoza Pascual, “Abadologio del monasterio de Samos...”, pág. 489, núm. 95).

${ }^{54}$ Para fray Pedro Martínez, véase Manuel Martínez AÑíbarro y Rives, Intento de un Diccionario biográfico y Bibliográfico de autores de la provincia de Burgos, Madrid, Imprenta y Fundición de Manuel Tello, 1889, págs. 341-345, y Lena S. Iglesias Rouco y María José Zaparaín Yáñez, "El monasterio de San Pedro de Cardeña, centro dinamizador del desarrollo artístico burgalés en los primeros decenios del siglo XVIII. Aportación a su estudio", Boletín de la Institución Fernán González, año LXXVIII, núm. 220 (2000/1), págs. 112-140.

${ }^{55}$ Ceán Bermúdez refiere que "ya era arquitecto á los veinte y tres años de edad, cuando su virtud le llevó al monasterio de benedictinos de S. Pedro de Cardeña, donde tomó el hábito de lego con el fin de servir á Dios y á la religion, haciendo de maestro de obras, título con que suelen confundirse buenos y malos arquitectos. Profesó el dia 8 de diciembre de 1698, y se mudó el nombre de bautismo en el de Pedro." (J. A. CEÁn Bermúdez, “Adiciones” a las Noticias de los arquitectos y arquitectura de España ..., t. IV, pág. 119). ${ }^{56}$ M. a del C. Folgar de la CALle, "La iglesia del monasterio de Samos...", págs. 295b-296a y 298b-299a. Cfr. lo que afirman Iglesias Rouco y Zaparaín Yáñez: "nada consta sobre sus actividades antes de ingresar, con 22 años, en el monasterio de San Pedro de Cardeña” (L. S. Iglesias Rouco y M. J. Zaparaín Yáñez, "El monasterio de San Pedro de Cardeña...", pág. 113).
} 
creo que sería retrasar la fecha de aparición en escena del arquitecto burgalés hasta aquel año de 1698, cuando ya había entrado en religión, precisamente unas semanas antes de la santa visita a Samos del fray Anselmo de la Peña, General de la Congregación de San Benito, que es cuando se documenta fehacientemente el inicio de las obras del nuevo templo ${ }^{57}$. De cualquier manera, fray Pedro, con febril actividad en la diócesis de Burgos y otros lugares de Castilla y del antiguo reino de Asturias y León, pocas ocasiones tendría para visitar la obra de Samos y menos para dirigirla en persona ${ }^{58}$.

La siguiente campaña de trabajos es, precisamente, la relacionada con la dádiva del padre Feijoo: comenzó en 1734 y concluyó en 1748, con la consagración del templo el día de san Benito, 11 de julio de 1748, siendo abad el asturiano Andrés García (1745-1749; muerto en 1751) ${ }^{59}$. La reanudación de los trabajos en el templo se debió a la iniciativa del abad fray Antonio Benito de Rivera (1733-1737), su antiguo archivero ${ }^{60}$. En ella figura como maestro de obras fray Juan Vázquez (muerto en 1761), por otro nombre, Juan de Samos (por haber profesado aquí de lego), al que se le venía asignando la construcción de todo el inmueble $^{61}$. Su nombramiento, sin duda, estuvo motivado por el fallecimiento de fray Pedro Martínez el año anterior (1733). Vázquez fue asimismo responsable de la construcción del coro de monjes, completado con un elocuente e histórico programa iconográfico durante el primer abadiato de fray Eladio de Nóboa en

\footnotetext{
${ }^{57}$ El acta de la santa visita lleva la data de 31 de diciembre de 1698 y en ella se menciona a Pedro Martínez tanto en calidad de arquitecto como de lego de la orden (ápud M. a del C. Folgar de la CALLE, "La iglesia del monasterio de Samos...”, págs. 291b-292, nota 10). Véase también E. Zaragoza Pascual, “Abadologio del monasterio de Samos...", pág. 489, núm. 95, citado supra en la nota 53.

${ }^{58}$ L. S. Iglesias Rouco y M. a J. Zaparaín YÁÑez, "El monasterio de San Pedro de Cardeña...”, págs. 116117. M. a del C. Folgar De la Calle, "La iglesia del monasterio de Samos...", pág. $299 a$.

${ }^{59}$ E. Zaragoza Pascual, "Abadologio del monasterio de Samos...”, págs. 492-493, núm. 110. M. Arias Cuenllas, Historia del monasterio de San Julián de Samos, pág. 533.

${ }^{60}$ Fray Antonio Benito de Rivera es el autor de la Serie chronológica de los abbades de Samos desde el año de 759... asta el pressente de 1736, publicada por E. ZARAGOZA PASCUAL, "Un abadologio inédito de Samos...”, págs. 307-343; para Rivera, véase pág. 341, núm. 103, nota 123. E. ZARAGOZA PAScuAL, “Abadologio del monasterio de Samos...”, pág. 492, núm. 107. En las obras también estuvieron comprometidos los abades fray Antonio Arias (1737-1741), Millán Esquerro (1741-1745), Andrés García (1749-1749) y Vicente Marín (1757-1761): véase E. Zaragoza Pascual, "Abadologio del monasterio de Samos...”, págs. [491] y 492-493, núms. (106), 108, 109, 110 y 113. M. Arias Cuenllas, Historia del monasterio de San Julián de Samos, pág. 533.

${ }^{61}$ Plácido Arias y Arias (OSB), "El R. P. Fr. Juan Vázquez, arquitecto de la magnífica Iglesia de Samos", Boletín de la Comisión Provincial de Monumentos Históricos y Artísticos de Lugo, t. I, núm. 1 (1941), págs. 16-17. M. Durán, La Real Abadía de Samos..., págs. 41-42. P. Arias, Historia del Real Monasterio de Samos, págs. 250-253, 265 y 425. E. Zaragoza i Pascual, "Libros de gradas de benedictinos...", pág. 883. M. Arias Cuenllas, Historia del monasterio de San Julián de Samos, págs. 329-330.

62 M. Arias Cuenllas, Historia del monasterio de San Julián de Samos, págs. 277, nota 12, y 533-534. El coro ocupaba los dos primeros tramos de la nave central de la iglesia; fue desmantelado en 1967-1968 (M. Arias Cuenllas, Historia del monasterio de San Julián de Samos, pág. 506; P. de la Portilla, San Julián de Samos..., págs. 25 y 26, y Antonio Garrido Moreno, “Juan Monleón Sapiña. Proyectos y reformas en
} 
1749-1753, ${ }^{62}$ de la sacristía ${ }^{63}$, el claustro grande (comenzado durante el segundo mandato de fray José Laguna [1693-1701] y concluido, junto con la portería [1757], durante el primero de fray Vicente Marín [1757-1761; muerto en 1773] $)^{64}$ y del levantamiento del segundo piso del claustro regular (o gótico), así como de la fuente de las Nereidas que hay en su centro, en torno a 1713-1717, a lo que parece, su primer trabajo en Samos ${ }^{65}$. Goy Diz opina, por el contrario, que esta fuente es anterior, de finales del siglo XVI o comienzos del XVII, porque acusa la influencia de los caprichos ideados por Wendel Dietterlin (hacia 1550-1599) y Hans Vredeman de Vries (1527-1604), tratadistas del manierismo germano y nórdico ${ }^{66}$. Pero por lo mismo, la fuente de las Nereidas también podría ser de la fecha que se le ha venido asignando, porque fue en el siglo XVIII cuando, en realidad, se pusieron de moda aquellos diseños, dando paso a la proliferación de placas, formas geométricas y otras fantasías en la arquitectura del barroco tardío, sobre todo en Galicia, como es sabido. A este respecto, conviene recordar un esclarecedor texto de Ceán Bermúdez, El churriguerismo, escrito en 1816 que, premonitoria y perspicazmente trata de esto ${ }^{67}$. Además, hay que tener presente que el padre Feijoo, en el discurso vil del tomo VI del Theatro Crítico Universal (1. a edición, Madrid, 1734), "Sátyros, tritones, y nereidas", de su mucha erudición literaria y plástica sobre estos seres legendarios y pobladores de los mitos de la Antigüedad clásica, no cita, ni de pasada, tan singular y monumental fuente que, de haber existido durante su vida de lego en Samos (1690-1692), seguro que recordaría en ocasión tan a propósito. En el mismo error incurrió Gregorio Marañón, al imaginar que el interés por estos monstruos marinos le vendría al

el monasterio de Samos [1951-1976]", en María del Carmen Folgar de la Calle y Ana Goy Diz [coords.], San Xulián de Samos: historia y arte en un monasterio. Opus Monasticorum III, Santiago de Compostela, Xunta de Galicia. Consellería de Innovación e Industria, 2008, págs. 189-190).

${ }_{63}$ M. Durán, La Real Abadía de Samos..., págs. 51-52.

64 "Durante su primer abadiato edificó el ala occidental del claustro grande y la actual portería" (E. ZARagoza Pascual, “Abadologio del monasterio de Samos...”, pág. 493, núm. 113). A. LóPez PelÁez, El Monasterio de Samos..., pág. 89. M. Arias Cuenllas, Historia del monasterio de San Julián de Samos, págs. 531-532 y 534 .

65 Siendo abad fray Pedro Vea (1713-1717), véase supra, nota 51. E. Zaragoza PAscual, "Un abadologio inédito de Samos...”, pág. 339, nota 115, núm. 98. E. Zaragoza PAscual, “Abadologio del monasterio de Samos...", págs. 490-491. P. Arias, Historia del Real Monasterio de Samos, pág. 251. A. LóPez PelÁez, El monasterio de Samos..., pág. 89. M. Durán, La Real Abadía de Samos..., págs. 18 y 57-58. M. Arias Cuenllas, Historia del monasterio de San Julián de Samos, págs. 258-259, 329 y 532. M. a del C. Folgar DE la CALle, "La iglesia del monasterio de Samos...", págs. 291b, nota 7, y 299 b.

${ }^{66}$ A. E. Goy Diz, "La formulación de la arquitectura benedictina...", págs. 140-141.

67 Juan Agustín Cé́n Bermúdez, "El churriguerismo, discurso inédito" (leído en la Academia de la Historia el 15 de noviembre de 1816), Boletín de la Biblioteca Menéndez y Pelayo, núm. 6, año III (1921), págs. 285-300. Entre los muchos títulos que ha generado este asunto, por vía de ejemplo, véase Teodoro FALCón, "Influencia de los grabados fantásticos de Dietterlin en la arquitectura barroca sevillana", Laboratorio de Arte, 21 (2008-2009), Sevilla, págs. 117-134. 
benedictino de sus "años de adolescencia, en el monasterio de Samos", a la vista de esta "fuente maravillosa e insolente" ${ }^{6}$. La fuente de las Nereidas se llamó en un principio de Las Sirenas. De nuevo fue el padre Feijoo quien puntualizó sobre la naturaleza y diferencias de estas quimeras, embrolladas por la imaginación popular, porque las cuatro figuras que en ella se representan a manera de tornapuntas son, en realidad, nereidas (mujeres con extremidades de pez) y no sirenas (pájaros con cabezas femeninas). Ello resulta de interés para la iconografía y uso de pintores, a quienes expresamente señala Feijoo, porque es frecuente "en los Professores de este Arte, por ignorancia de la Historia, y la Fábula" confundir unas con otras ${ }^{69}$.

Hasta 1734, fray Juan había estado dirigiendo la construcción de la iglesia (cabecera y crucero) del monasterio de San Salvador de Villanueva de Lorenzana (Lugo), que él mismo había proyectado, sucediéndole desde entonces Fernando de Casas y Nóvoa, que finalmente la concluyó con un nuevo y más innovador planteamiento $^{70}$.

Precisamente fue aquel año cuando fray Juan Vázquez asumió la dirección y continuación de las obras de la iglesia de $\operatorname{Samos}^{71}$. Por el documento de cesión de derechos de edición de 1734 que ahora se publica, parece que no debía ser mucho lo erigido del nuevo templo hasta entonces y que el viejo se hallaba en pleno uso. En él se dice que el monasterio de San Julián de Samos “está prezisado a la edificazión de nuevo templo porque el anttiguo, sobre ser yncódomo e yncompetentte a la grandeza de dicho Real monastterio, esttá por su mucha anttigüedad amenazando ruina, y no ttener los medios prezisos y nezesarios para perfizionar dicha fábrica etc.” (Apéndices, documento 1).

Lo mismo se deduce de lo que el padre Sarmiento comentó del monasterio de Samos en su Manifiesto de 1743 (como ya advirtió Bonet Correa), pues señaló que "está casi fabricando Iglesia nueva, porque la antigua era mala, vieja, pequeña, y fabricada en falso"72. La demolición del templo medieval fue urgida por el avance de los trabajos en el nuevo, para dejar sitio al último tramo de la nave meridional y al sotacoro, y según afirma la arquitecta Estefanía López Salas, se

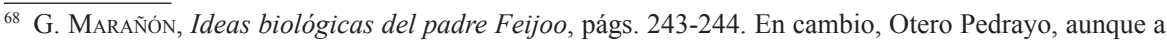
vuela pie, escribe muy acertadamente que "es posible que [Feijoo] no viera la fuente de las Nereidas", aunque opina que es "problemática su fecha, por los años 1713 a 17" (R. Otero Pedrayo, El padre Feijoo..., pág. 72).

${ }_{69}$ Así lo aclara el padre Feijoo en el Theatro Crítico Universal, t. VI, vII, § viii-41. G. MARAÑón, Ideas biológicas del padre Feijoo, pág. 244, nota 1. M. Durán, La Real Abadía de Samos ..., pág. 58.

${ }^{70}$ Datos dispersos de fray Juan, en José Couselo BouzAs, Galicia Artística en el siglo XVIII y primer tercio del XIX, Compostela, Imprenta, Librería y Enc. del Seminario, MCмXXXIII [1933], págs. 39, 238, 333 y 404 , y Apéndice I, págs. 663-664.

${ }^{71}$ M. ${ }^{a}$ del C. Folgar de la Calle, "La iglesia del monasterio de Samos...", pág. $301 a$.

${ }^{72}$ M. SARmiento, Manifiesto del recibo de rentas de los monasterios..., págs. 115-116 (citado por A. Bonet Correa, La arquitectura en Galicia ..., pág. 555, nota 30).
} 


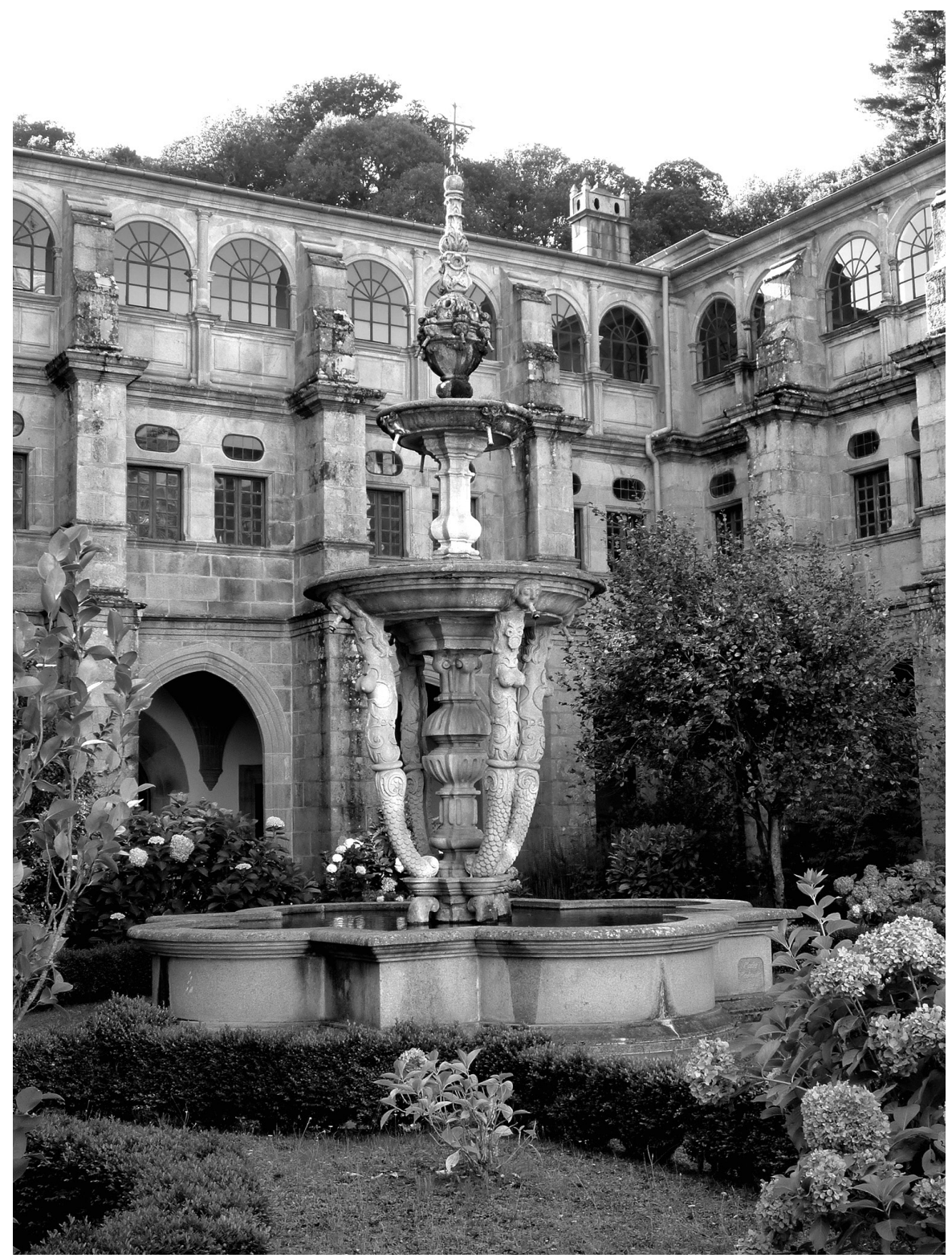

Fray Juan de Samos, Fuente de las Nereidas (1713-1717), claustro gótico de Samos.

Fotografía del autor. 
verificó en 1746. Por último, durante el abadiato de fray Vicente Marín (17571761) se construyó lo que quedaba de la crujía occidental del claustro grande y la portería del monasterio, pieza que, precisamente, está en línea y es adyacente a la fachada de la iglesia nueva ${ }^{73}$.

De cualquier manera, la sacristía, cabecera, transepto y primeros tramos de las naves de la iglesia, así como gran parte del claustro nuevo (salvo el ángulo noroccidental y la portería) debían estar construidos por aquel año 1734, porque durante el abadiato de fray Antonio Arias (1729-1733) consta la construcción de los dos órganos y la donación de los frontales para los retablos de Nuestra Señora y San Benito, localizados en el transepto ${ }^{74}$.

Folgar demuestra y comenta que el plan de fray Pedro Martínez sigue la pauta estética del clasicismo que tanto arraigo tuvo en el ámbito castellano, sobre todo, en la escuela vallisoletana desde la última década del siglo xvı y hasta sobrepasada la mitad del XVII. La elección de la planta (de las llamadas "jesuíticas") y del orden toscano; la regularidad en las proporciones, el escaso realce de los elementos arquitectónicos y de las molduras; la limpieza de los paramentos, con la alternancia del muro encalado y el sillar de granito, o los casetones reticulados de las bóvedas y cúpula remiten a un estilo y práctica constructiva de, al menos, tres cuartos de siglo anterior y al grandioso templo de San Martín Pinario, en Santiago de Compostela ${ }^{75}$. El característico abombamiento del friso (de inequívoco origen palladiano) es otro detalle que conviene añadir a lo dicho por Folgar de la Calle y que va en abono de su argumentación.

El estilo de la iglesia, por tanto, es clasicista, como ejemplo intemporal de la estética postherreriana; en cambio, la fachada (inacabada en su remate) es barroca, con influencias en los detalles decorativos del barroco manierista, de inspiración geométrica, cultivado por el ensamblador Simón Rodríguez y los arquitectos Clemente Fernández Sarela y Lucas Ferro Caaveiro. Corresponde su fábrica a la segunda mitad del siglo XvIII. La estatua en piedra de San Benito del nicho prin-

\footnotetext{
73 E. López Salas, "Propuesta metodológica para la restitución de la planimetría de una arquitectura medieval desaparecida...", págs. 3, 15 y 18. "Durante su primer abadiato [fray Vicente Marín] edificó el ala occidental del claustro grande y la actual portería" (E. Zaragoza PASCUAL, "Abadologio del monasterio de Samos...", pág. 493, núm. 113). M. a del C. Folgar de la CAlle, "La iglesia del monasterio de Samos...", pág. $302 b$. De la iglesia antigua se conserva parte de los muros del ángulo SO y la portada lateral del penúltimo tramo de la nave meridional (tardorrománica, del primer cuarto del siglo XIII), que constituyen la pared interior del primer tramo (ángulo NE) de la crujía septentrional del claustro gótico (M. CASTRO, "Un monasterio gallego", págs. 140-141. M. Durán, La Real Abadía de Samos ..., planta del monasterio, Madrid, octubre de 1942, figs. 6 y 7, y págs. 31-39. E. López SALAs, "Propuesta metodológica para la restitución de la planimetría de una arquitectura medieval desaparecida...").

74 E. Zaragoza Pascual, "Un abadologio inédito de Samos...”, pág. 341, núm. 102.

75 Este particular ya lo puso de relieve el arquitecto M. Durán (La Real Abadía de Samos ..., págs. 40-42) y lo reiteró A. Bonet Correa (La arquitectura en Galicia..., pág. 558). La iglesia de San Martín Pinario (1626-1637) es de Bartolomé Fernández Lechuga.
} 
cipal de la fachada es de José Ferreiro, de $1784-1785 .^{76} \mathrm{Y}$ acaso sea por aquellos años cuando se dio por concluida definitivamente la fachada del templo ${ }^{77}$, si bien la monumental escalera está fechada en $1779^{78}$.

Uno de los sucesos más señalados de la moderna historia de Samos fue el incendio que entre el 24 y 26 de septiembre de 1951 arrasó el monasterio. Las llamas asolaron los dos recintos claustrales (incluida la biblioteca) pero no el templo ni la sacristía, que solo resultaron parcialmente afectados en sus cubiertas. Los trabajos de reconstrucción, comenzados de modo casi inmediato, duraron casi nueve años. El monasterio actual fue reinaugurado el 14 de septiembre de $1960 .^{79}$

\section{LA DÁDIVA DEL PADRE FEIJOO EN CIFRAS}

La resolución definitiva de los trabajos en la iglesia de Samos se produjo a raíz del traspaso que el padre Feijoo hizo al monasterio de los derechos de edición y del producto de las ventas de los seis primeros tomos del Theatro Crítico Universal y de la Ilustración apologética al primero y segundo tomo del Theatro Crítico. Por el estudio de la producción editorial de Benito Jerónimo Feijoo realizado por José Miguel Caso y Silverio Cerra, sabemos que en el periodo comprendido entre 1734 y 1744 se hicieron doce ediciones (si no más) del Theatro Crítico Universal y dos de la Ilustración apologética ${ }^{80}$. El detalle de ellas lo hemos puesto por apéndice en la tabla 1. Resulta llamativo que la primera edición del Theatro Crítico (1726) se editara sin privilegio (solo con licencia); la razón es que nadie esperaba un éxito semejante. Así que la primera reimpresión, efectuada al año siguiente, a los once

\footnotetext{
$\overline{{ }_{76}}$ M. Arias Cuenllas, Historia del monasterio de San Julián de Samos, págs. 278, 305, 321 y 323, y José Manuel B. López VÁzQuez, "Los retablos neoclásicos del monasterio de Samos", en María del Carmen Folgar de la Calle y Ana Goy Diz (coords.), San Xulián de Samos: historia y arte en un monasterio. Opus Monasticorum III, Santiago de Compostela, Xunta de Galicia. Consellería de Innovación e Industria, 2008, pág. 235

77 M. a del C. Folgar de la Calle, "La iglesia del monasterio de Samos...", pág. 302, nota 64.

${ }_{78}$ Mediante una inscripción partida: “AÑO” - "1779.” (M. ARIAs CuEnllas, Historia del monasterio de San Julián de Samos, pág. 278).

${ }^{79}$ El incendio acaeció durante el abadiato de fray Mauro Gómez Pereira (Samos, 1895-1977; abad entre 1930 y 1972) y tuvo amplia repercusión en la prensa: por ejemplo, Antonio CAMUÑAs, "El Real Monasterio Abadía de San Julián, de Samos", diario $A B C$, Madrid, 4 de diciembre de 1951, pág. 9, y en el NO-DO (núm. 463A de 19 de noviembre de 1951). Véanse E. Zaragoza Pascual, "Abadologio del monasterio de Samos...”, págs. 501-502, núm. 138, y recientemente, Estefanía López SALAS, "Las causas y las consecuencias del incendio de 1951 en el monasterio de San Julián de Samos. Nuevos datos para su estudio", Cuadernos de Estudios Gallegos, LXIII, núm. 129 (2016), págs. 417-447.

${ }^{80}$ J. M. Caso y S. Cerra, Benito Jerónimo Feijoo. Bibliografia ..., estado de las págs. XX-XXI del "Prólogo", y núms. 14 g y 14 h; 100 e y 100 g; 113 e y 113 f; 131 c y 131 d; 164 b y 164 c; 167 a, 167 b y 167 c para el Theatro Crítico; y 128 c y 128 d para la Ilustración apologética. Más recientemente, también François Lopez se interesó por la edición de las obras de Feijoo y el número de volúmenes impresos (F. LoPEz, "La obra de Feijoo en la historia de la edición española...”, págs. 317-336).
} 
meses de la prínceps, ya salió con él, dado en San Ildefonso, el 6 de octubre de 1726, y para diez años ${ }^{81}$.

El monto económico de la explotación editorial de estas ediciones se ignora; no se conoce registro de ella, pero sin duda hubo de ser cuantioso y no "muy mermado", como insinuaba el padre Plácido Arias, que adujo para ello los muchos dineros empleados por Feijoo en limosnas ${ }^{82}$. No obstante, puede ser estimado revisando las tasas de esos libros y teniendo presentes los criterios de Caso González ${ }^{83}$. En el Prólogo a la Bibliografía del Padre Feijoo, razonaba el profesor Caso acerca del volumen estimado de los libros editados por Feijoo durante su vida y del número de ejemplares que conformaba cada edición y las sucesivas reimpresiones. Según el padre Martín Sarmiento, la primera impresión del tomo IV del Theatro Crítico Universal (Madrid, 1730) fue de 2.250 ejemplares $^{84}$. Y el propio Feijoo señalaba que de la primera estampación de los tomos V y VI del Theatro "se han tirado tres mil" ". Pero si tomamos un término medio de dos mil para cada estampación (bastante bajo, casi un tercio menor a la vista de lo referido por los interesados) en el periodo de referencia (1734-1744), en que se pusieron a la venta doce impresiones del Theatro, se alcanzaría la cifra de 24.000 volúmenes. Y para la Ilustración apologética, que conoció dos, unos 4.000. Según la tasa, cada ejemplar en rama del Theatro Crítico (todos los volúmenes tienen una extensión parecida: entre 440 y 468 páginas) se tendría que vender a trece reales, y de la Ilustración apologética (240 páginas), a siete (en ambos casos, omito las fracciones de maravedíes $)^{86}$. Del tomo primero del Theatro Crítico (1726) consta el precio de venta

\footnotetext{
${ }_{81}$ Theatro Crítico Universal, tomo primero. Segunda impresión. Con privilegio, Madrid, Imprenta de Lorenzo Francisco Mojados, MDCCXXVII [1727], págs. [18-19]. El anuncio se publicó en la Gaceta de Madrid, núm. 32, del martes, 12 de agosto de 1727, pág. 218. J. M. CASo y S. CERRA, Benito Jerónimo Feijoo. Bibliografía..., núm. 14 b pág. 10.

${ }^{82}$ P. ARIAS, "El P. Feijóo y la Iglesia de Samos". Sobre la caridad del padre Feijoo, véase supra, notas 12 y 13 .

${ }^{83}$ Una explicación de la legislación y de los trámites que durante el Antiguo Régimen precisaba la edición de libros en España y sobre el significado y contenido de las páginas preliminares lo podemos ver en Agustín GonzÁlez de Amezúa y Mayo, "Cómo se hacía un libro en nuestro Siglo de Oro" [1946], en Opúsculos históricos-literarios, Madrid, Consejo Superior de Investigaciones Científicas, 1951, t. I, págs. 331-373. ${ }^{84}$ Fray Martín SARmiento, Demonstración crítico-apologética del Theatro Crítico Universal, que dio a luz el R. P. M. Fr. Benito Geronymo Feijoo, Benedictino, etc. Tomo primero, Madrid, Viuda de Francisco del Hierro, 1732, pág. [2] del Prólogo. Dato recogido y comentado por V. de la FuENTE, "Preliminares", pág. XXVII, y J. M. CAso, "Prólogo" a Benito Jerónimo Feijoo. Bibliografía..., pág. xxII, y núm. 155 a, pág. 86. La historia circunstanciada de las ediciones de las obras de Feijoo ("los Anales Tipográficos de la publicación de las Obras del P. Feijoo") figura en la "Noticia de la Vida y Obras del M. I. y R. P. D. Fr. Benito Gerónimo Feijoo...”, escrita por Campomanes (véase supra, nota 4), págs. XXXVIII-XLIII.

85 Theatro Crítico Universal. Tomo VI, Madrid, 1734, Prólogo, págs. XLI-XLII.

${ }^{86}$ La tasa para las reediciones del Theatro fue de 8 maravedíes el pliego; el volumen de los seis primeros tomos es muy regular y está entre los 55 y 57 pliegos. El mismo precio se estableció para las de la Ilustración apologética (el volumen tiene 30 pliegos). En el ejemplar de la Ilustración apologética (ed. de 1734) que conserva la Biblioteca del Instituto Feijoo de Estudios del Siglo XVIII de la Universidad de Oviedo,
} 
al público: Otero Pedrayo refiere que se vendía a dos reales de a ocho, o sea, a dieciséis reales ${ }^{87}$. Lo que en conjunto ascendería a 340.000 reales. De ellos hay que descontar el coste de producción, porque la impresión corría por cuenta del monasterio de Samos (que "ymprimiere a su costta el espresado monastterio", dice el documento de cesión). Si este lo cifráramos (muy por alto y exagerado) en la mitad del producto de la venta, estaríamos manejando una cantidad cercana a los 170.000 reales netos, si no más; y si en un tercio (acaso más cerca de lo real), los ingresos podrían haber ascendido a unos 226.666 reales, o sea: casi un cuarto de millón de reales. Sin duda, un pingüe regalo, determinante para dar cima a la construcción de la tan esperada iglesia en un plazo más que razonable de casi catorce años (desde 1734 hasta 1748, según expresan sendas inscripciones en los brazos del transepto $)^{88}$.

Finalmente, la iglesia fue consagrada el 11 de julio (festividad de san Benito de Nursia) de 1748, y desde Manuel Murguía se viene repitiendo que con la asistencia del padre Feijoo, que "predicó el sermón". Pero esta especie no se ha podido contrastar. Parte de un comentario que fray Juan Ramón Guitián, monje exclaustrado y párroco por entonces de Samos, hizo a Murguía durante la visita al antiguo monasterio en 1860 o 1861 y que este recogió en el Diccionario de escritores gallegos ${ }^{89}$. Sería muy señalado que así hubiera sido, pero más parece deseo que realidad, pues no consta documentalmente (por ejemplo, en los abadologios) ni en los anales del monasterio un acontecimiento tan relevante, dada la personalidad de Feijoo y su edad, un anciano a punto de cumplir... isetenta y dos años! Un anciano, sí, pero con una mala salud de hierro.

En efecto, son frecuentes las referencias a la salud del Padre Maestro, acaso un sujeto afectado de hipocondría. Y además, “de cuerpo enfermizo desde la edad de diez i nueve. [...] porque el vejestorio Feijoo quiere vivir para sí lo poco que le resta de vivir", confiesa él mismo a fray Martín Sarmiento en una carta fechada en Oviedo, el 17 de septiembre de 1740, es decir, casi ocho años antes de la consagración del templo de Samos ${ }^{90}$. En el tomo III del Theatro Crítico (Madrid, 1729), hasta en dos ocasiones alude Feijoo a temas de salud: en el

\footnotetext{
leemos en las guardas "Comprado en Junio de 1736 en Madrid, por 6. rs"; pero quizás se tratara de una adquisición de segunda mano.

87 R. Otero Pedrayo, El Padre Feijoo..., pág. 133.

88 “CO/MENZOSE. / AÑO / 1734” y “ACA/BOSE. / AÑo / 1748”, en dos medallas, con letras doradas, en los remates de los arcosolios que contienen los retablos de San Benito (lado de la epístola) y de la Inmaculada, respectivamente.

${ }^{89}$ M. Murguía, Diccionario de escritores gallegos, págs. 199-200, nota, y 201, nota; y a partir de él, M. Arias Cuenllas, "Catorce cartas de Feijoo al P. Sarmiento", págs. 19-20. M. Arias Cuenllas, Historia del monasterio de San Julián de Samos, págs. 270, nota 7, 276-277, y 403-405. M. a del C. FolgAR DE LA Calle, "La iglesia del monasterio de Samos...", pág. $302 a$.

${ }^{0}$ M. Arias Cuenllas, "Catorce cartas de Feijoo al P. Sarmiento”, carta núm. 7, págs. 36-42.
} 
"Prólogo apologético" (§ 1, pág. [29]), se disculpa por la tardanza en dar a luz esta nueva entrega, porque "continuaron tan porfiadas mis indisposiciones, que en muy pocos ratos pude tomar la pluma por el espacio de siete meses"; y en "La verdad vindicada, contra la Medicina vindicada. Respuesta apologética" ( 1,1 , pág. 335), traducción del discurso que había escrito en latín y publicado en el tomo II el año anterior, empieza argumentando que "siendo yo de una salud bastantemente quebrantada...". Incluso los padres aprobantes de este tomo, hermanos suyos en el claustro de San Vicente de Oviedo (“Aprobación”, pág. [13]), notan que "la falta de salud le precisa muchas veces (con harto dolor nuestro) a suspender los vuelos de su discurso", y el tiempo que "el Autor gasta en medio de los muchos frangentes de salud (que son tan frequentes, que casi llegan a ser continuos)". A su flaca salud, también se refiere el benedictino en otros lugares: así, en el "Prólogo al lector" de la Ilustración apologética al primero, y segundo tomo del Theatro Crítico (Madrid, 1729, págs. [31 y 32]), afirma que "No me atrevo à ofrecerte luego el quarto tomo, porque mi salud es poca, y mis ocupaciones muchas... Todo esto junto con que yo, por mi complexion, soy de corta resistencia al trabajo, aun quando gozo buena salud, hace que esta Obra camine con mas perezoso passo, que el que tu, y yo quisiéramos". En fin, en "Algunas advertencias sobre los sermones de missiones" $"$, dice que cuando se jubiló de su cátedra universitaria en junio de 1739 (nueve años antes de la consagración del templo de Samos), le hubiera apetecido predicar en misiones, pero que, entre otras cosas, se lo impidió su propia naturaleza, porque "la debilidad del pecho era totalmente incorregible, siendo tan connatural à mi nativo temperamento, que aun en la adolescencia, y juventud, padecì el mismo defecto" de la falta de "robustéz de pecho", o sea, de lo que se podría entender como asma. De las enfermedades y patologías padecidas por Feijoo a lo largo de su vida trata Gregorio Marañón ${ }^{92}$.

Y siendo ya mayor, tampoco fue muy dado a viajar, quizás debido a ese carácter aprensivo tan acusado: solo se conocen tres breves estancias en Madrid: una, en el verano de 1726, para preparar la edición del tomo I del Theatro Crítico, y la última, en $1728 .{ }^{93}$

A don Manuel Murguía (o por mejor decir, al exclaustrado Guitián) también se debe la invención de la celda del monasterio de Samos que hoy lleva el nombre de Feijoo, una leyenda generada entonces, cuando el monasterio estaba abandonado y en ruinas, pero que no tiene fundamento alguno. El tiempo que el Padre Maestro residió en Samos fue el de su noviciado (1690-1692), momento en el que además aún no se había iniciado la construcción del claustro grande, recinto donde se

\footnotetext{
$\overline{{ }^{1} \text { Carta v, } \S 2}$, del t. V de Cartas eruditas, y curiosas, Madrid, Joachín Ibarra, 1760, pág. 164.

92 "Vida patológica de Feijóo", en G. Marañón, Las ideas biológicas del padre Feijóo, págs. 296-302.

93 R. Otero Pedrayo, El padre Feijoo..., págs. 134 y 157-166.
} 
encuentra aquella estancia (situada en el ángulo suroriental del claustro nuevo, asomada al río Sarria) que, en realidad, fue la antigua abacial ${ }^{94}$.

De cómo Feijoo gestionaba la publicación y comercialización de sus obras tenemos algunos datos ${ }^{95}$. Por aquel entonces (1734-ante 1739), asistía al padre benedictino un fraile cursante en Oviedo, fray Benito de Arenas, hijo de San Salvador de Oña ${ }^{96}$. Era el padre fray Martín Sarmiento, conventual en el monasterio de San Martín de Madrid, el responsable de preparar los originales para la imprenta, tramitar los permisos de publicación, censuras, privilegios, tasas, correcciones y fes de erratas, así como de supervisar la producción editorial, siempre en las prensas madrileñas, pues el Padre Maestro remitía los originales desde Oviedo, ya que en esta no se imprimió nada de su obra crítica ${ }^{97}$. En cambio, la venta de sus libros, la recaudación de ingresos y su administración eran gestionadas por el padre Vallejo ("el hidalguísimo Vallejo", al que amaba "por su mucha bondad i honrradez"), predicador en el mismo monasterio madrileño, fallecido a comienzos del verano de 1748. De la encuadernación se encargaban los padres fray Sebastián de Vergara (muerto también en 1748), abad del monasterio de San Martín (17291733) y luego visitador general de la Congregación (1733-1737), y a partir de 1734, el mencionado Vallejo ${ }^{98}$. Hasta 1764 , la venta de los libros se despachaba principalmente en las porterías de los monasterios de la orden, siendo el de San Martín de Madrid el principal distribuidor de las obras del padre Feijoo, como consta en los anuncios de la Gaceta de Madrid y en algunos pies de imprenta ${ }^{99}$.

\footnotetext{
94 M. Murguía, Diccionario de escritores gallegos, pág. $199 \mathrm{~b}$.

95 Pero no se conservan los manuscritos originales de ellas, ni siquiera trazas. Véase lo que a este respecto comentaba el padre fray Benito Uría, que lo achacaba a su ánimo humilde, porque "tan poco aprecio hacía de sus preciosos Originales, que llegò à emplear algunos en humildes ministerios, y acaso huvieran perecido todos, si el Religioso, que le assistía no huviera tenido la advertencia, y cuidado de recogerle los restantes", que, si se conservaron algún tiempo (acaso en el monasterio de Samos, con el resto de su biblioteca), no han llegado a nuestros días (fray Benito URÍA, Oración fúnebre, que en las solemnes exequias celebradas a la buena memoria de el Ill. ${ }^{m o}$ y R. ${ }^{m o}$ Don Fr. Benito Geronymo Feijoó, en el Colegio de San Vicente de Oviedo dia 17. de diciembre de 1764. dixo el P. Maestro Fr. Benito Uría, etc., Salamanca, Antonio Villargordo y Alcaràz [1765], pág. 21).

96 Theatro Crítico Universal. Tomo VIII, Madrid, 1739, discurso x, "Paradoxas médicas. Paradoxa XIX. Elección de Agua", § 161.

97 Gregorio Marañón, siempre feliz en sus expresiones, llama a Sarmiento el "cónsul" de Feijoo en Madrid (G. MARAÑón, Ideas biológicas del padre Feijóo, pág. 138 y pássim). A este consulado ya se refirió M. Murguía, Diccionario de escritores gallegos, pág. 212a, y de la faceta de Sarmiento como almacén de erudición y debelador de los impugnadores de las obras del maestro Feijoo, habla en particular Antolín LóPEZ Peláez (presb.), "Sarmiento en defensa de Feijóo", Revista Contemporánea, año xxIII, t. CV, cuaderno III (1897), págs. 232-233 y pássim. También M. Arias Cuenllas, Historia del monasterio de San Julián de Samos, págs. 302-304, y F. Lopez, "La obra de Feijoo en la historia de la edición española...”, pág. 324.

${ }_{98}$ M. Arias Cuenllas, "Catorce cartas de Feijoo al P. Sarmiento", págs. 12 y 20; núms. 4, 7, 11 y 13 , págs. 31, nota 40, 36, nota 48, 59, nota 57, y 60-61; y Apéndice, núms. 1 y 2, págs. 65-69.

99 Los anuncios son de este tenor: "El Libro nuevo en quarto: Theatro Critico universal, su Autor el Padre Maestro Fray Benito Feyjòo, Benedictino, se vende en la Porteria del Convento de San Martin de esta
} 
De este privilegio privativo que favorecía a las órdenes religiosas frente a los impresores y libreros, trata un elocuente documento que publicó François Lopez ${ }^{100}$.

Las sumas ingresadas por la quinta edición conjunta de 1781 (también llamada "edición de Samos") ${ }^{101}$, fallecido ya Feijoo y cuya explotación editorial correspondió en exclusiva a este monasterio, se emplearon para financiar el retablo mayor ${ }^{102}$ y concluir la sacristía ${ }^{103}$. Pero esta edición, o no se vendió toda de inmediato o si no, se iba reimprimiendo con el mismo pie de imprenta y año (1781), pues hay referencias a "los caudales que producen las obras del reverendísimo Feixoo" en las actas de las Visitas de los Padres Generales al monasterio de Samos desde 1778 (?) hasta $1821 .{ }^{104} \mathrm{O}$ ¿será debido a una reiteración formal y retórica de los mandatos de los padres Generales? Algunos ejemplares de Samos llevan un ex libris especial, de propiedad de edición ("De $\mid D$. Gerónimo Feixoo $|y|$ Montenegro."), que resulta algo equívoco, porque podría dar a entender que proceden de la librería particular del padre Feijoo, lo que es imposible, atendiendo a las fechas de publicación (1781) y de fallecimiento del benedictino $(1764)^{105}$. En todo caso,

Corte". Es el de la puesta a la venta del primer tomo del Theatro (Gaceta de Madrid, núm. 36, del martes 3 de septiembre de 1726, pág. 148). Otras referencias, por vía de ejemplo y solo hasta 1734: Gaceta de Madrid, núm. 32, del martes 12 de agosto de 1727, pág. 218 (primera reimpresión, corregida, del t. I); Gaceta de Madrid, núm. 14, del martes 6 de abril de 1728, pág. 56 (t. II, primera ed.); Gaceta de Madrid, núm. 22, del martes 31 de mayo de 1729, pág. 122 (t. III, primera ed.); Gaceta de Madrid, núm. 2, del martes 10 de enero de 1730, pág. 8 (Ilustración apologética). Gaceta de Madrid, núm. 52, del martes 26 de diciembre de 1730, pág. 208 (t. IV del Theatro Crítico); Gaceta de Madrid, núm. 28, del martes 8 de julio de 1732, pág. 120 (t. II, 3. a reimpresión); Gaceta de Madrid, núm. 5, del martes 3 de febrero de 1733, pág. 20 (t. I, 5. ${ }^{a}$ reimpresión); Gaceta de Madrid, núm. 27, del martes 7 de julio de 1733, pág. 112 (t. V del Theatro); y Gaceta de Madrid, núm. 35, del martes 31 de agosto de 1734, pág. 176 (t. VI del Theatro).

${ }^{100}$ F. Lopez, "La obra de Feijoo en la historia de la edición española...", pág. 328.

${ }^{101}$ J. M. Caso y S. Cerra, Benito Jerónimo Feijoo. Bibliografía ..., núm. 382, págs. 213-215.

${ }^{102}$ El retablo mayor fue diseñado en Madrid por el académico Miguel Fernández; es obra de Juan Antonio Domínguez de Estibada, datada en 1780 y consagrada en 1785 (M. DurÁn, La Real Abadía de Samos..., pág. 43); armoniza muy bien con las líneas clásicas de la capilla e iglesia. El grupo de San Julián (en el cuerpo de gloria), las estatuas de Santa Basilisa y Santa Cristina y el relieve de la Transfiguración del tímpano son del escultor compostelano José Ferreiro (M. Durán, La Real Abadía de Samos..., pág. 44). Para este retablo, véanse M. Arias CuEnLlas, Historia del monasterio de San Julián de Samos, págs. 278, 305, 321 y 323, y J. M. B. LóPez VÁzquez, "Los retablos neoclásicos del monasterio de Samos”, págs. 223-231. ${ }^{103}$ V. GonZÁlez, El padre Feijoo y su monasterio de Samos, pág. 10.

${ }^{104}$ Es la cláusula 15 . $^{a}$ de los mandatos: véanse Libro IV, años 1778,1782 y 1787, fols. $60 r, 181 r v$ y $347 v$; Libro V, años 1792 y 1793, fols. $116 r$ y $224 v$; Libro VI, años 1798,1802 y 1815 , fols. $85 v$, $173 r$ y $261 r$; y Libro VII, año 1821, fol. 260v. Consultadas por la transcripción que figura en el disco compacto (CD) que acompaña al libro de María del Carmen Folgar de la Calle y Ana Goy Diz (coords.), San Xulián de Samos: historia y arte de un monasterio. Opus Monasticorum III, Santiago de Compostela, Xunta de Galicia. Consellería de Innovación e Industria, 2008. Los libros de Visitas se conservan en el Archivo del Monasterio de Silos (Burgos) y en el de San Pelayo de Antealtares (Santiago de Compostela), y fueron extractados por E. Zaragoza PAScual, "Visitas de los Generales de Valladolid...”, pág. 66 (visita del año 1827 [sic pro 1821]).

${ }^{105}$ Véase El Remate, subastas. Libros y manuscritos. Subasta 125, Madrid, jueves, 21 de marzo de 2013, lotes núms. 18, 267 y 1.395 , págs. 4, 29 y 100. 


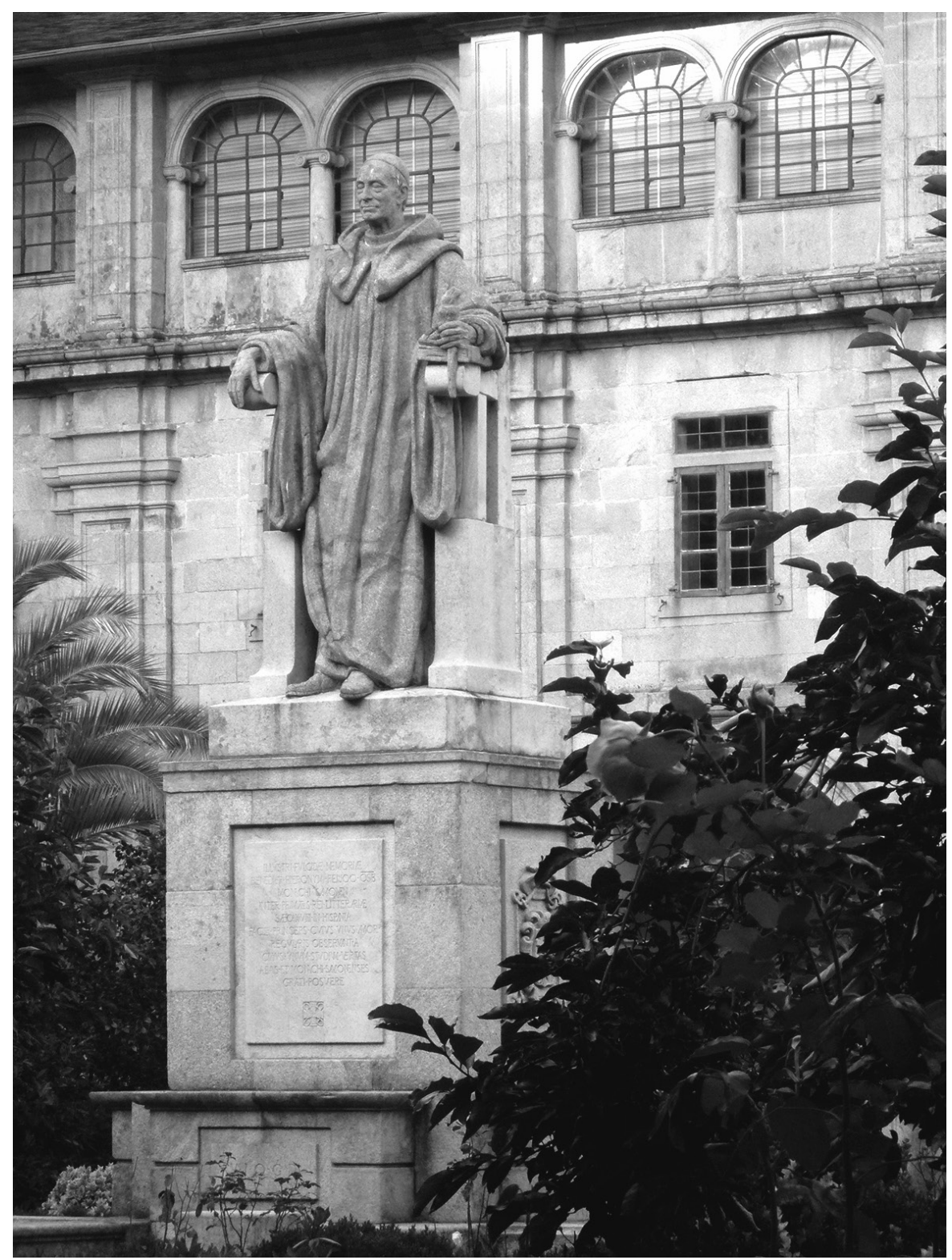

Francisco Asorey, Monumento al padre Feijoo (1947), claustro grande, o de Feijoo, del monasterio de Samos. Fotografía del autor. 
no parece que por entonces se pueda decir que el mercado estuviera saturado de ejemplares de los escritos de Feijoo, porque tras la de Samos, todavía hubo otra edición conjunta en 1784, la sexta, a cargo del impresor Benito Cosculluela en Pamplona. La integran quince volúmenes y se concluyó en $1787 .{ }^{106}$ Se trata de la última edición de la obra completa, no solo de aquel siglo, sino hasta el presente.

La deuda de Feijoo con Samos, la casa donde profesó y que costeó su formación y estudios, la hizo explícita el sabio benedictino en la dedicatoria del tercer tomo del Theatro Crítico Universal (1729), al afirmar que "mi amor à esse Sagrado Monasterio se mide por mi obligación, y la obligación es tan grande, que solo puede satisfacer con el amor. ... Lo que yo debo à esse Ilustríssimo Monasterio, cabe en mi conocimiento, no en mi voz, ni en mi pluma. ... mas siempre contaré por el mayor de todos la enseñanza que debí à essa ilustre Escuela de virtud, Theatro donde se desengaña de los errores de el Mundo, harto mejor, que el Mundo puede desengañarse de sus errores en mi Theatro" (Apéndices, documento 2) ${ }^{107}$. A su vez, la deuda contraída por el monasterio de Samos con su hijo y benefactor se saldó en el siglo xx, con la erección del monumento a su memoria en el claustro grande: es la estatua del Padre Feijoo, de Francisco Asorey González (Cambados, Pontevedra, 1889-Santiago de Compostela, 1961), inaugurada el 24 de agosto de 1947 con la pompa y solemnidad de aquellos tiempos y que desde entonces da nombre y confiere personalidad a este monumental recinto ${ }^{108}$.

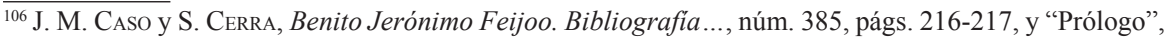
pág. XXIII.

${ }^{107}$ Comenta todo esto V. GonzÁlez, El padre Feijoo y su monasterio de Samos.

${ }^{108}$ Se erigió siendo abad fray Mauro Gómez Pereira (E. Zaragoza Pascual, "Abadologio del monasterio de Samos...”, pág. 501, núm. 138). P. Arias, Historia del Real Monasterio de Samos, págs. 417-419. Ramón Otero TúÑez, "Iconografía del Padre Feijoo. Esculturas", en El P. Feijoo y su siglo. Ponencias y comunicaciones presentadas al Simposio celebrado en la Universidad de Oviedo del 28 de septiembre al 5 de octubre de 1964, vol. III, Oviedo, Universidad de Oviedo, 1966, págs. 556-558. M. Arias CuEnLlas, Historia del monasterio de San Julián de Samos, pág. 488. Enrique Fernández CastiñeIras y Juan M. Monterroso Montero, “¡Bien está fray Benito en su abadía! Samos, el padre Feijoo y Asorey, un universo en un claustro", en María del Carmen Folgar de la Calle y Ana Goy Diz (coords.), San Xulián de Samos: historia y arte en un monasterio. Opus Monasticorum III, Santiago de Compostela, Xunta de Galicia. Consellería de Innovación e Industria, 2008, págs. 277-291.
} 


\section{APÉNDICES}

DocUMENTOS

1734, septiembre 18. Oviedo, Real Colegio de San Vicente (OSB)

El padre fray Benito Jerónimo Feijoo traspasa los derechos de impresión y reimpresión y los beneficios de la venta de los seis primeros tomos del Theatro Crítico Universal y de la Ilustración apologética durante diez años al monasterio benedictino de San Julián de Samos (Lugo) para financiar la construcción de la nueva iglesia.

Archivo Histórico de Asturias (Oviedo): ante Melchor de Huergo Valdés, caja 7.700, año 1734 , fol. $88 r v$.

OBSERVACIONES: márgenes ligeramente afectados por la humedad. Se ha transcrito resolviendo las abreviaturas y añadiendo tildes y signos de puntuación ortográficos modernos para facilitar la lectura.

\section{"Cesión hecha por el Maestro Feixóo a fauor del Real Monasterio de Samos.}

En el Real Colexio de San Vizentte, horden de San Benito, de esta ciudad de Oviedo, á diez y ocho días de el mes de septiembre de el año de mill settezientos y treintta y quattro, ante mí, escribano, y testtigos, el Reverendo Padre Maestro fray Benito Feijoô, Maestro General por su Religión, doctor y cathedráttico de Vísperas en la ynsigne Vniversidad de estta dicha ciudad, con lizenzia, permiso y beneplázito que para el conttexto de este ynstrumento le fue dada y conzedida por el Reverendísimo Padre Maestro fray Joseph Pérez, abad de él, que la azeptó, doy fee. Y de ella vsando, otorga que por quantto con el motiuo de que el Monasterio de su professión, que es el Real de San Julián de Samos, sitto y fundado en el Reino de Galizia y Prouinzia de Lugo, está prezisado a la edificazión de nueuo templo porque el anttiguo, sobre ser yncódomo e yncompetentte a la grandeza de dicho Real Monastterio, esttá por su mucha anttigüedad amenazando ruina, y no ttener los medios prezisos y nezesarios para perfizionar dicha fábrica, á fin de concurrir como amantte hijo de dicho Real Monastterio, donde reziuió el santo áuito y professión, en el modo que puede con algún subsidio á tan piadoso fin, zede, renunzia y traspasa, en aquella mejor vía y forma que lugar haia en derecho, más firme y valedero sea, en dicho Real Monastterio de Samos y su comunidad los preuilejios que por zédulas reales a obttenido de Su Majestad (Dios le guarde) 
para ympremir y reympremir por espazio de diez años los seis tomos primeros de el Theatro crítico y la Ylusttrazión apoloxéttica, dejándole consiguienttemente por enttero a dicho Real Monastterio el producto de la ventta de los libros que, en virtud de la traspasazión de dichos preuilejios, ymprimiere a su costta el espresado Monastterio. Y porque esta zessión tenga todo el valor que de derecho se requiere y es nezesario, vajo de la dicha lizenzia que le fue dada y conzedida, como ba dicho, se apartta de el derecho que tenía para dicha ympressión y lo zede, renunzia y traspasa en el espresado Monastterio de Samos para que por virttud de ella y de dichos preuilejios y zédulas reales puedan ymprimir e ympriman unos y otros tomos por el espresado tiempo, aprobechándose de todo el productto que rindieren para los fines y efecttos que ba declarado. Y se apartta Su Reverendísima de el derecho, dominio, aczión y posessión que tenía por dicho tiempo para la dicha ympressión, zediéndole por él en el dicho Real Monastterio y su comunidad para que vsen en todo y por todo durantte los diez años $\left.\right|^{\text {fol. } 88 v}$ de su conzessión e ympressión dando poder y plena faculttad en ttoda forma a dicho Real Monastterio para su vso y ventta, cui[ $a]$ zessión, que lleba hecho, no alterará en cosa ni en partte, anttes vien, quier[e] tenga prontto y deuido cumplimientto por ser así su volunttad y zeder como zede en vn venefizio tam [sic] pío como es el que se a de ejecutar en dicho rehedifizio. Para cuio cumplimientto da poder a las justtizias de Su Majestad compettenttes de su fuero, para que a ello le puedan compeler; y lo rezibe por senttenzia difinitiba de juez compettentte, pasada en auttoridad de cosa juzgada, sobre que renunzió todas leyes de su fauor, con la General de el Derecho en forma, y las reglas, fueros y esttatuttos de su sagrada Religión. Assí lo otorgó y firmó juntto con dicho reverendísimo Padre Abad, a quienes doy fee conozco, estando presenttes por testtigos Gerónimo Moral, Juan de el Pra[do] Valdés y Domingo Reinares, vezinos y residenttes en estta dicha Ciudad.

\section{fr. Joseph Pérez, Abad de San Vicente [rubricado]. Fr. Benito Feijoo [rubricado].}

Antte my:

Melchor de Huergo Valdés [rubricado]". 
1728, diciembre 13. Oviedo, Real Colegio de San Vicente (OSB)

Dedicatoria al monasterio de San Julián de Samos del tomo III del Theatro Crítico Universal (1. ${ }^{a}$ ed., Madrid, 1729). El texto que reproducimos es el de la quinta edición conjunta de las Obras de Feijoo, hecha a expensas del Real Monasterio de Samos (Madrid, Blas Román, Impresor de la Real Academia de Derecho Español y Público, MDCCLXXXI [1781], págs. III-X).

"MUY R. ${ }^{\mathrm{Do}} \mathrm{P} . \mathrm{ABAD}, \mathrm{Y}$ SANTO CONVENTO.

El amor, y el agradecimiento concurren à presentar à $V^{s} P^{\text {des }}$ este libro; aunque siendo el obsequio tan corto, es preciso dexe al agradecimiento empeñado, y al amor mal satisfecho. Tributo tan humilde, ni para el agradecimiento es recompensa, ni para el amor bizarría.

Mi amor à esse Sagrado Monasterio se mide por mi obligacion, y la obligacion es tan grande, que solo puede satisfacer con el amor. No hay cariño mas noble, que aquel que nace de el agradecimiento, ni agradecimiento mas infeliz, que aquel que solo puede pagar con el cariño. Carga el hijo con la deuda del padre: pension que impuso la Ley natural à su ilustre cuna. Y al fin, el agradecimiento queda desconsolado, porque no puede corresponder de otro modo; y el amor triste, porque à lo que es obligacion no puede llamarlo fineza.

Lo que yo debo à esse Ilustrissimo Monasterio, cabe en mi conocimiento, no en mi voz, ni en mi pluma. Desde la edad de catorce años, no del todo cumplidos, en que me introduxo superior llamamiento por sus sagrados umbrales, hasta la hora presente, me ha estado siempre lloviendo beneficios; mas siempre contaré por el mayor de todos la enseñanza, que debi à essa ilustre Escuela de virtud, Theatro donde se desengaña de los errores de el Mundo, harto mejor, que el Mundo puede desengañarse de sus errores en mi Theatro. Lastima es, que por la indocilidad del terreno no haya correspondido el fruto al cultivo. Pero esta memoria, por lo mismo que me confunde, me consuela, contemplando mi propria confusion, como señal de que no se perdió de el todo la semilla.

Assi como el mayor de los beneficios, que debo à esse Monasterio, es la instruccion saludable que me dió en mis primeros años, la mayor de sus glorias, siendo tan sublimes, y tantas, es la continuada succession de la mas austera observancia Regular por tantos siglos. Los Monges que le fundaron, hijos del celebérrimo, y antiquissimo Monasterio Agaliense, al transferirse de la Imperial Toledo à essas Montañas, llevaron consigo el espíritu de los Ildefonsos, de los Heladios, y de otros insignes Varones que España sacó de aquel Claustro, para 
ocupar gloriosamente sus mejores Sillas. Una misma es, no distinta, la Comunidad de Samos de la Agaliense, por haverse trasladado de una parte à otra todo el cuerpo del Convento, y con el cuerpo toda el alma de la vida Monastica. El impulso, que regía el movimiento de aquellos Fundadores, se conoce en el sitio, que eligieron para la fundación. Tan ansiosos iban de retirarse del bullicio del Mundo, que poco les faltó para esconderse aun del Cielo. Tan recogido, tan estrecho, tan sepultado está esse Monasterio entre quatro elevados montes, que por todas partes no solo le cierran, mas le oprimen, que solo es visto de las Estrellas, quando las logra Verticales, y los que han estado en él pueden presumir haver hallado respuesta al famoso Problema de Virgilio:

Dic quibus in terris, \& eris mihi magnus Apollo,

Tres pateat Cœli spatium, non amplius ulnas.

La disposición del parage, retrata la Religión de sus habitadores. La retrata, y aun la influye: porque cerrado por todas partes el Horizonte, faltan objetos donde se dissipe el espiritu. Solo ázia el Cielo tiene la vista desahogo, y assí se lleva todas las atenciones el Cielo. iQué ajustado viene aqui, assi para la Religión de el Monasterio, como para la Topographia del sitio, lo que de un antiguo Luco se lee en el libro octavo de la Eneida!

Religione Patrum late sacer, undique colles

Inclusere cavi.

Pero en vano nuestros antiguos Monges buscaron aquel triste retiro, que la Naturaleza havía formado para Fieras; y la Gracia destinado para Angeles. En vano, digo, en orden al efecto de ser ignorados de los hombres; pues los hombres fueron à buscar los Angeles entre las Fieras. Presto llegó à noticia de Papas, y Reyes la preciosa Mina, que ocultaban aquellos riscos. Assi desde los principios empezaron à estimar en tan alto grado al Monasterio de Samos, que dudo haya havido Comunidad alguna Religiosa, que les debiesse mas generosas atenciones. Los Reyes le dieron tanta autoridad sobre sus vassallos, que apenas un Principe Soberano la tiene mayor en sus Dominios; pues no solo le concedieron todos los derechos, y pechos Reales, con el nombre de Omne opus Fiscale, y las penas que llaman de Camara, de homicidio, \& adulterio; pero mandaron, que ningun Gobernador, ò Tribunal Real se entendiesse sobre materia alguna con dichos vassallos, sí solo el Abad de Samos: Non respondeant nisi Abbati Samonensi. Son palabras de el Privilegio. Pero esta jurisdiccion temporal, por su no uso, se perdió con el 
tiempo. Bastabale ser temporal, para que aquellos Monges, que atendian solo à las importancias del alma, descuidassen de su conservacion. Bien que consta, que aun subsistía en tiempo del Rey D. Pedro, pues este Principe, en la confirmacion que hizo de todos los Privilegios de la Casa, limitó algo la Soberanía de sus Abades, concediendo à los Ministros Reales poder entrar en el territorio de la Abadía, unicamente en el caso que algun homicida de los Dominios de el Rey se refugiasse en él, y el Abad no consintiesse en su entrega.

Los Papas dieron à los Abades una amplissima jurisdiccion espiritual, que comprehende en circunferencia siete, ù ocho leguas de territorio, con independencia igual en su linea; esto es, con inmediacion à la Silla Apostolica, y sin subordinacion alguna al Metropolitano, como hoy la gozan, sin la menor contestacion.

Ni es prueba inferior à la de arriba del gran concepto en que los Reyes de España tenian al Monasterio de Samos, haver el Rey Don Fruela puesto en él para educacion à su hijo Don Alonso, llamado el Casto, como se afirma en el Privilegio del Rey Don Ordoño el Segundo, expedido por los años de 922. Aunque pudieramos amplificar mas esta gloria con la probabilidad de que el Rey Casto vistió la Cogulla en el mismo Monasterio, teniendo à favor de ella à nuestro excelente Chronista el Maestro Yepes, nos abstenemos de ello, por no haver en el Archivo del Monasterio Privilegio, ò Escritura alguna que lo expresse.

La singular felicidad de no haver tenido jamás Abad Comendatorio esse Monasterio, haviendo sido en todos tiempos tan poderoso, es otro argumento eficacissimo de la especialissima aceptacion, que lograban los Monges en el conocimiento de los Principes. El grato olor de virtud, que exalaban sus corazones encendidos en el fuego de la caridad, era tan grande, que no pudiendo contenerse en el ambiente vecino, humeaba hasta las alturas del Solio. Tal fue siempre el Monasterio de Samos. Tal es el dia de hoy; pues en $V^{s} P{ }^{\text {des }}$ veo repetidos los exemplos, y copiadas las virtudes de tantos ilustres predecessores. Ruego al Altissimo continúe esta felicidad por muchos siglos, y à $V^{s} P^{\text {des }}$ conserve la vida en su santa gracia por muchos años. San Vicente de Oviedo. Diciembre 13. de 1728.

Humilde, y amante hijo de V. ${ }^{\text {s }}{ }^{\text {des }}$

Q. B. S. M.

Fr. Benito Feyjoó”. 
TABLA

1734-1744

Resumen de las ediciones y reimpresiones del Theatro Crítico Universal y de la Ilustración apologética de fray Benito Jerónimo Feijoo entre 1734 y 1744, correspondiente al periodo del privilegio de cesión de los beneficios por la venta de estas obras al monasterio de San Julián de Samos. Elaboración propia a partir de los datos extraídos de José Miguel Caso González y Silverio Cerra Suárez, Benito Jerónimo Feijoo. Obras completas. Tomo I. Bibliografia, Oviedo, Cátedra Feijoo - Centro de Estudios del Siglo XVIII, 1981, estado de las págs. XX-XXI del "Prólogo", y núms. 14 g y 14 h; 100 e y $100 \mathrm{~g} ; 113$ e y 113 f; 131 c y 131 d; 164 b y 164 c; 167 a, 167 b y 167 c para el Theatro Crítico; y 128 c y 128 d para la Ilustración apologética.

A. Theatro Crítico Universal, ò Discursos varios, en todo género de materias, para desengaño de errores comunes

Tomo I (1. ${ }^{\mathrm{a}}$ ed., Madrid, Imprenta de Lorenzo Francisco Mojados, MDCCXXVI [1726]); sexta y séptima reimpresión, Madrid, Imprenta de los Herederos de Francisco del Hierro, MDCCXXXVII [1737] y MDCCXLII [1742].

Tomo II (1. ${ }^{a}$ ed., Madrid, Imprenta de Francisco del Hierro, MDCCXXVIII [1728]); cuarta y quinta reimpresión, Madrid, Imprenta de los Herederos de Francisco del Hierro, MDCCXXXvi [1736] y MDCCXLI [1741].

Tomo III (1. ${ }^{\text {a }}$ ed., Madrid, Imprenta de Francisco del Hierro, MDCCXXIX [1729]); cuarta y quinta reimpresión, Madrid, Imprenta de los Herederos de Francisco del Hierro, MDCCXXXVII [1737] y MDCCXLI [1741].

Tomo IV (1. a ed., Madrid, Imprenta de la Viuda de Francisco del Hierro, MDCCXXX [1730]); tercera y cuarta reimpresión, Madrid, Imprenta de los Herederos de Francisco del Hierro, MDCCXXXVII [1737] y MDCCXLII [1742].

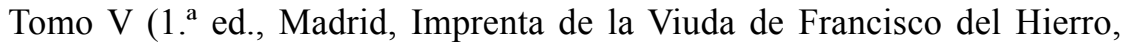
MDCCXXXIII [1733]); segunda y tercera reimpresión, Madrid, Imprenta de los Herederos de Francisco del Hierro, MDCCXXXVII [1737] y MDCCXLII [1742].

Tomo VI, Madrid, Imprenta de los Herederos de Francisco del Hierro, MDCCXXXIV [1734]; segunda y tercera reimpresión, Madrid, Imprenta de los Herederos de Francisco del Hierro, MDCCXXXVIII [1738] y 1742 (pero no registrada por Caso y Cerra). 
B. Ilustración apologética al primero, y segundo tomo del Theatro Crítico, etc.

(1. ${ }^{\mathrm{a}}$ ed., Madrid, Francisco del Hierro, MDCCXXIx [1729]); tercera y cuarta reimpresión, Madrid, Herederos de Francisco del Hierro, MDCCXXXIV [1734] y MDCCXXXVII [1737].

\section{BIBLIOGRAFÍA}

Anchóriz, José María, "Biografía y juicio de las obras que escribió el Ilustrísimo y Reverendísimo Padre Fray Benito Gerónimo Feijóo, del Consejo de S. M., Maestro General de la Orden de San Benito de la reforma de Valladolid", en Discurso leído en la solemne apertura de los estudios de la Universidad Literaria de Oviedo el día $1 .^{\circ}$ de octubre de 1857, por don José María Anchóriz, doctor en Jurisprudencia y en Letras, Catedrático de Literatura Latina en la misma Universidad, socio de la academia de arqueología etc., Oviedo, Imprenta y Litografía de Brid, Regadera y Comp., 1857.

Arias y Arias, Plácido (OSB), "El R. P. Fr. Juan Vázquez, arquitecto de la magnífica Iglesia de Samos", Boletín de la Comisión Provincial de Monumentos Históricos y Artísticos de Lugo, t. I, núm. 1 (1941), Lugo, págs. 16-17.

Arias y Arias, Plácido (OSB), "El P. Feijóo y la Iglesia de Samos", Boletín de la Comisión Provincial de Monumentos Históricos y Artísticos de Lugo, t. II, núms. 14-15 (1945), Lugo, págs. 51-53.

Arias y Arias, Plácido (OSB), Historia del Real Monasterio de Samos, Santiago de Compostela, Imprenta, Lib. y Enc. del Seminario Conciliar, 1950 (hay reed. facsimilar: A Coruña, Libros Dixitec, S. L., 2011).

Arias Cuenllas, Maximino (OSB), Un abadologio inédito del monasterio de Samos [hacia 1722-1724]. Presentación, transcripción y notas por el P. Maximino Arias, Samos, Monasterio de Samos, 1968 (Publicaciones de la Real Abadía de Samos, IV; es tirada aparte de Archivos leoneses, núm. 22 [1968], León, págs. 207-272).

Arias Cuenllas, Maximino (OSB), "Catorce cartas de Feijoo al P. Sarmiento" [seguidas del apéndice: "Dos cartas de Feijoo al P. Vallejo"], Boletín del Centro de Estudios del Siglo XVIII, núms. 4-5 (1977), Oviedo, Universidad de Oviedo, págs. 5-69 (reeditado en Yermo. Cuadernos de historia y de espiritualidad monásticas, vol. 20, núms. 1-2 [1982], Madrid, Monasterio de Santa María del Paular, págs. 173-210).

Arias Cuenllas, Maximino (OSB), Historia del monasterio de San Julián de Samos, Samos (Lugo), Monasterio de Samos, 1992.

Bonet Correa, Antonio, La arquitectura en Galicia durante el siglo XVII, Madrid, Consejo Superior de Investigaciones Científicas, 1966 (reed. en 1984).

Campomanes, véase [Rodríguez Campomanes, Pedro].

Caso González, José Miguel, y Cerra Suárez, Silverio, Benito Jerónimo Feijoo. Obras completas. Tomo I. Bibliografia, Oviedo, Cátedra Feijoo. Centro de Estudios del Siglo XVIII, 1981. 
Castro, Manuel, "Un monasterio gallego [San Julián de Samos]", Boletín de la Comisión Provincial de Monumentos Históricos y Artísticos de Orense, t. IV, núms. 82-86 (1912), Orense, págs. 113-120, 136-143, 163-171, 189-195 y 201-208.

Ceán Bermúdez, Juan Agustín, Diccionario histórico de los más ilustres profesores de las Bellas Artes en España. Compuesto por D. ... y publicado por la Real Academia de S. Fernando, Madrid, Imprenta de la Viuda de Ibarra, 1800, 6 tomos.

Ceán Bermúdez, Juan Agustín, “Adiciones" a las Noticias de los arquitectos y arquitectura de España desde su Restauración, por el Excmo. Señor D. Eugenio Llaguno y Amírola, ilustradas y acrecentadas con notas, adiciones y documentos por D. Juan Agustín CeánBermúdez, Madrid, Imprenta Real, 1829, 4 tomos.

Ceán Bermúdez, Juan Agustín, "El churriguerismo, discurso inédito" (leído en la Academia de la Historia el 15 de noviembre de 1816), Boletín de la Biblioteca Menéndez y Pelayo, año III, núm. 6 (1921), Santander, págs. 285-300.

Constituciones de la Congregación de Nvestro Glorioso Padre San Benito de España, è Inglaterra. Avgmentadas, y añadidas con las nuevas Difiniciones, que desde el año de 1610. hasta el de 1701. han sido establecidas, y aprobadas en diversos Capitulos. Y el día de oy tienen ya fuerza de Leyes. Recopiladas, y redvcidas a mejor Methodo, y orden, por los Comissarios que la Santa Congregacion nombrò, y señalò para su Recopilacion, en su Capitulo General de 1701. Impressas en Madrid a costa de la Congregacion, En la Oficina de la Viuda de Melchor Alvarez. Año de 1706.

Couselo Bouzas, José, Galicia Artística en el siglo XVIII y primer tercio del XIX, Compostela, Imprenta, Librería y Enc. del Seminario, MCMXXXIII [1933] (hay reed. moderna: Santiago de Compostela, MmIv [2004]).

Durán, Miguel (arquitecto), La Real Abadía de San Julián de Samos. Estudio HistóricoArqueológico, Madrid, Blass, S. A., 1947.

Feijoo, Benito Jerónimo, “Autobiografía del Rvmo. P. Feijóo", Anales de la Universidad de Oviedo. Tomo IV - 1905-1907, Oviedo, Establecimiento Tipográfico, 1907, págs. 379-381 (es una carta a Gregorio Mayans, fechada en Oviedo, el 3 de enero de 1733).

Folgar de la Calle, María del Carmen, "La iglesia del monasterio de San Julián de Samos: fray Pedro Martínez y fray Juan Vázquez", en María del Carmen Folgar de la Calle, Ana Goy Diz y José Manuel B. López Vázquez (coords.), Memoria artis. Studia in memoriam M. ${ }^{a}$ Dolores Vila Jato, Santiago de Compostela, Xunta de Galicia, 2003, t. I, págs. 289-309.

Folgar de la Calle, María del Carmen, "Iter operis o la relación sobre la definición de la fábrica del monasterio samonense: la construcción de la nueva iglesia y de un nuevo claustro", en María del Carmen Folgar de la Calle y Ana Goy Diz (coords.), San Xulián de Samos: historia y arte en un monasterio. Opus Monasticorum III, Santiago de Compostela, Xunta de Galicia. Consellería de Innovación e Industria, 2008, págs. 149-180.

Folgar de la Calle, María del Carmen y Goy Diz, Ana (coords.), "San Xulián de Samos: historia y arte de un monasterio. Opus Monasticorum III", Santiago de Compostela, Xunta de Galicia. Consellería de Innovación e Industria, 2008

Francos Arango, Alonso (presb.), Oración fúnebre, que en las solemnes exequias que la Universidad de Oviedo consagró en el día 27. de noviembre de este año de 1764. a la immortal memoria del Ilustrissimo, y Reverendissimo S. D. F. Benito Geronimo Feijoó y Montenegro, del Consejo de S. M. y Cathedratico de Prima Jubilado en ella. Dixo el 
S. Doct. D. Alonso Francos Arango, Colegial que fuè en el Mayor del Arzobispo de la Vniversidad de Salamanca, y en élla Cathedratico de Philosophia, Canonigo Magistral de la Santa Yglesia de Tuy, Visitador General, y Examinador Synodàl de aquèl Obispado, y al presente Canonigo Magistral, y Dignidad Maestre-Scuela de la Santa Yglesia de Oviedo, Examinador Synodal de este Obispado, y Calificador de la Suprema, y General Inquisicion, Oviedo, Francisco Díaz Pedregal, 1765.

Fuente, Vicente de la, "Preliminares" a Obras escogidas del Padre Fray Benito Jerónimo Feijoo y Montenegro, Maestro general de la religión de San Benito, del Consejo de S. M., etc., etc. Con una Noticia de su vida y juicio crítico de sus obras por Don Vicente de la Fuente, Madrid, M. Rivadeneyra - Impresor - Editor, 1863 (Biblioteca de Autores Españoles, desde la formación del lenguaje hasta nuestros días, t. LVI), págs. V-LIV.

Garrido Moreno, Antonio, "Juan Monleón Sapiña. Proyectos y reformas en el monasterio de Samos (1951-1976)”, en María del Carmen Folgar de la Calle y Ana Goy Diz (coords.), San Xulián de Samos: historia y arte en un monasterio. Opus Monasticorum III, Santiago de Compostela, Xunta de Galicia. Consellería de Innovación e Industria, 2008, págs. 181-192.

González, Victoriano (OSB), El padre Feijoo y su monasterio de Samos, Lugo, Tipografía “La Voz de la Verdad", 1966 (Publicaciones de la Real Abadía de Samos, II). Se trata del texto de una conferencia dictada en Samos, el 18 de septiembre de 1964. Publicado de nuevo en Yermo. Cuadernos de historia y de espiritualidad monásticas, vol. 20, núms. 1-2 (1982), Madrid, Monasterio de Santa María del Paular, págs. 149-171.

González de Amezúa y Mayo, Agustín, "Cómo se hacía un libro en nuestro Siglo de Oro" [1946], en Opúsculos históricos-literarios, t. I, Madrid, Consejo Superior de Investigaciones Científicas, 1951, págs. 331-373.

González Santos, Javier, "Martínez Bustamante, Francisco Antonio", en Apéndice de la Gran Enciclopedia Asturiana (1981-1991), t. XX, Gijón, Silverio Cañada, Ed., 1996, págs. 10-12.

González Santos, Javier, "Iconografía dieciochista del padre Feijoo. Un estudio del mercado editorial y su incidencia en la difusión de la imagen del sabio benedictino", en Inmaculada Urzainqui (ed.), Feijoo, hoy. Semana Marañón 2000, Oviedo, Fundación Gregorio Marañón Instituto Feijoo de Estudios del Siglo XVIII, 2003, págs. 159-224.

Goy Diz, Ana E., "La formulación de la arquitectura benedictina tras la incorporación a la Congregación. El monasterio de Xulián de Samos”, en María del Carmen Folgar de la Calle y Ana Goy Diz (coords.), San Xulián de Samos: historia y arte en un monasterio. Opus Monasticorum III, Santiago de Compostela, Xunta de Galicia. Consellería de Innovación e Industria, 2008, págs. 129-148.

Hevia Ballina, Agustín, "Hacia una reconstrucción de la librería particular del P. Feijoo", Studium Ovetense, 4 (1976), Oviedo, págs. 139-186.

Hevia Ballina, Agustín, "Un nuevo acercamiento al Padre Feijoo: el catálogo de la librería del monasterio de San Vicente de Oviedo", Studium Ovetense, 8 (1980), Oviedo, págs. 311-346.

Hevia Ballina, Agustín, "El Padre Feijoo, hombre de la Ilustración: sus aficiones históricogeográficas”, Studium Ovetense, 9 (1981), Oviedo, págs. 29-57.

Hevia Ballina, Agustín, "La biblioteca clásica del P. Feijoo", en II Simposio sobre el Padre Feijoo y su siglo (ponencias y comunicaciones), vol. 1, Oviedo, Centro de Estudios del Siglo XVIII. Universidad de Oviedo, 1981, págs. 375-392.

Hevia Ballina, Agustín, "Libros de medicina en la librería particular del Padre Feijoo", Studium Ovetense, 10 (1982), Oviedo, págs. 31-46. 
Iglesias Rouco, Lena S., y Zaparaín Yáñez, María José, "El monasterio de San Pedro de Cardeña, centro dinamizador del desarrollo artístico burgalés en los primeros decenios del siglo XVIII. Aportación a su estudio", Boletín de la Institución Fernán González, año LXXVIII, núm. 220 (2000/1), Burgos, págs. 107-140.

Lopez, François, "La obra de Feijoo en la historia de la edición española (siglo XVIII)", en Inmaculada Urzainqui (ed.), Feijoo, hoy. Semana Marañón 2000, Oviedo, Fundación Gregorio Marañón - Instituto Feijoo de Estudios del Siglo XVIII, 2003, págs. 317-336.

López Caderón, Marica, "La obra del "escultor y arquitecto" Francisco de Moure en San Xulián de Samos", en María del Carmen Folgar de la Calle y Ana Goy Diz (coords.), San Xulián de Samos: historia y arte en un monasterio. Opus Monasticorum III, Santiago de Compostela, Xunta de Galicia. Consellería de Innovación e Industria, 2008, págs. 193-208.

López Peláez, Antolín (presbítero), El Monasterio de Samos. Estudio histórico... Con un M. S. inédito del P. Sarmiento, Lugo, Imprenta á cargo de Juan M. Bravo, 1894 (hay reed. facsimilar: A Coruña, Libros Dixitec, S. L., 2011).

López Peláez, Antolín (presbítero), “Sarmiento en defensa de Feijóo", Revista Contemporánea, año XXIII, t. CV, cuaderno III (1897), Madrid, 15 de febrero, págs. 225-246.

López Salas, Estefanía, "Propuesta metodológica para la restitución de la planimetría de una arquitectura medieval desaparecida: la iglesia románica del monasterio de San Julián de Samos (Lugo)", Arqueología de la Arquitectura, 10 (2013), Madrid-Vitoria, CSICUniversidad del País Vasco, págs. 1-19.

López Salas, Estefanía, "Las causas y las consecuencias del incendio de 1951 en el monasterio de San Julián de Samos. Nuevos datos para su estudio", Cuadernos de Estudios Gallegos, LXIII, núm. 129 (2016), Santiago de Compostela, Instituto de Estudios Gallegos "Padre Sarmiento" - CSIC, págs. 417-447.

López Vázquez, José Manuel B., "Los retablos neoclásicos del monasterio de Samos”, en María del Carmen Folgar de la Calle y Ana Goy Diz (coords.), San Xulián de Samos: historia y arte en un monasterio. Opus Monasticorum III, Santiago de Compostela, Xunta de Galicia. Consellería de Innovación e Industria, 2008, págs. 223-237.

Marañón, Gregorio, Las ideas biológicas del padre Feijóo, Madrid, Espasa-Calpe, S. A., 1941 (2. ${ }^{\mathrm{a}}$ ed.; 1. ${ }^{\mathrm{a}}$ ed.: Madrid, 1934).

Martínez Añíbarro y Rives, Manuel, Intento de un Diccionario biográfico y Bibliográfico de autores de la provincia de Burgos, Madrid, Imprenta y Fundición de Manuel Tello, 1889 (hay reed. facsimilar: Valladolid, Consejería de Cultura y Turismo, 1993).

Morayta Sagrario, Miguel, "El Padre Feyjoó", La Ilustración Española y Americana, año XX, núms. XXXVII y XXXVIII (1876), Madrid, 8 y 15 de octubre, págs. 206-207 y 233-234.

Murguía, Manuel, Diccionario de escritores gallegos, Vigo, J. Compañel, Editor, MDCCCLXII [1862; en realidad, se editó en 1864], págs. 199-212.

Murguía, Manuel, "Fray Benito Jerónimo Feijoo y Montenegro", en La aldea de Casdemiro. Álbum literario dedicado á la inmortal memoria del ilustre crítico Padre Feijóo, publicado por El Heraldo Gallego, con la colaboración de distinguidos escritores, Orense, Imprenta de La Propaganda Gallega, 1876 (reed. de la cédula contenida en la entrada precedente).

Noval, Guadalupe de la (OSB), "Cuatro cartas autógrafas del P. Feijoo al P. Martín Sarmiento", Yermo. Cuadernos de historia y de espiritualidad monásticas, vol. 2 (1964), Madrid, Monasterio de Santa María del Paular, págs. 259-265. 
Nóboa, fray Heladio de (OSB), Oración fúnebre en las exequias, que en 22. de enero de 1765. celebrò el Real Monasterio de S. Julián de Samos, a su hijo el Mui Ilustre Señor, y $R^{m o}$. Padre Maestro F" Benito Feijoo [...]. Dixola el M. R. P. M. Fr. Heladio de Nóboa, Hijo, y Abad que ha sido de el mismo Monasterio, Maestro General, y Difinidor de la Religión de San Benito. Sácala a luz la Real Casa de Samos, Salamanca, Antonio Villargordo y Alcaràz, [1765] (hay otra edición: Madrid, Manuel Martín, 1765).

Otero Pedrayo, Ramón, El padre Feijóo: su vida, doctrina e influencias, Orense, Instituto de Estudios Orensanos "Padre Feijoo", 1972.

Otero Túñez, Ramón, "Iconografía del Padre Feijoo. Esculturas”, en El P. Feijoo y su siglo. Ponencias y comunicaciones presentadas al Simposio celebrado en la Universidad de Oviedo del 28 de septiembre al 5 de octubre de 1964, vol. III, Oviedo, Universidad de Oviedo, 1966, págs. 551-558.

[Pardo y Pardo, Francisco Javier, y Millán, José], Catálogo de las obras existentes en la Biblioteca Pública Provincial. Con una introducción del Dr. D. Germán Alonso Hortas, Lugo, Diputación Provincial de Lugo, 1935.

Pérez, Narciso (OSB), "La celda del P. Feijoo en Samos", Monásticon. Revista de información benedictina, II (1935), Samos, págs. 143-154 (reeditado por Victoriano González, El Padre Feijoo y su monasterio de Samos, Lugo, 1966, págs. 20-30).

Portilla, Pedro de la (OSB), "El monasterio de Samos: su arte", en Maximino Arias Cuenllas (OSB), Historia del monasterio de San Julián de Samos, Samos (Lugo), Monasterio de Samos, 1992, “Apéndice”, págs. 541-547 (editado por vez primera en la Gran Enciclopedia Gallega, t. XXVII, págs. 86-88).

Portilla, Pedro de la (OSB), San Julián de Samos: monasterio benedictino, León, Edilesa, 1993.

Portilla, Pedro de la (OSB), "El desaparecido retablo mayor de la antigua iglesia románica del Monasterio de S. Julián de Samos: estudio iconográfico", en Pedro de la Portilla (OSB, coord.), Miscelánea Samonense. Homenaje al P. Maximino Arias (OSB), Lugo, Diputación Provincial de Lugo. Servicio de Publicaciones, 2001, págs. 145-163.

Rey Castelao, Ofelia, "El monasterio de Samos en la Edad Moderna. La sombra del padre Feijoo", en María del Carmen Folgar de la Calle y Ana Goy Diz (coords.), San Xulián de Samos: historia y arte en un monasterio. Opus Monasticorum III, Santiago de Compostela, Xunta de Galicia. Consellería de Innovación e Industria, 2008, págs. 73-93.

Risco, Manuel (OSA), España Sagrada. Tomo XL. Antiguedades de la Ciudad y S. ${ }^{\text {ta }}$ Iglesia de Lugo: Memorias de los insignes Monasterios de S. Julian de Samos, y S. Vicente de Monforte. Etc., Madrid, Oficina de la Viuda é Hijo de Marín, MDCCXcvi [1796].

Risco, Manuel (OSA), España Sagrada. Tomo XLI. De la Santa Iglesia de Lugo: Continuación de su historia desde el siglo XII. hasta fines del XVIII. Etc., Madrid, Oficina de la Viuda é Hijo de Marín, MDCCXCVIII [1798].

[Rodríguez Campomanes, Pedro], "Noticia de la Vida y Obras del M. I. y R. P. D. Fr. Benito Gerónimo Feijoo, Monge Benedictino de la Congregación de España, Catedrático de Prima de Teología Jubilado de la Universidad de Oviedo, Maestro General por su Orden, del Consejo de S. M.”, figura al frente del t. I de la reedición del Teatro Crítico Universal, ... á costa de la Compañía de Impresores, y Libreros del Reyno, Madrid, Imprenta Real de la Gaceta, MDCCLXV [1765], págs. I-LVI. 
Sarmiento, fray Martín (OSB), Manifiesto del recibo de rentas de los monasterios, de la religión de San Benito; y en qué se emplean. Sacado y presentado al Consejo por el Rvmo. P. Mtro. Fr. Martín Sarmiento benedictino, Cronista General de su Religión: y de Indias por el Rey N. S.: en carta á un amigo que le consulta. Madrid. Año de 1743, Santiago, Biblioteca de "El Porvenir", 1879.

Uría, fray Benito (OSB), Oración fúnebre, que en las solemnes exequias celebradas a la buena memoria de el Ill. ${ }^{\text {mo }}$ y R. $^{\text {mo }}$ Don F. Benito Geronymo Feijoó, en el Colegio de San Vicente de Oviedo dia 17. de diciembre de 1764. dixo el P. Maestro Fr. Benito Uría, etc., Salamanca, Antonio Villargordo y Alcaraz [1765].

Vidart Schuch, Luis, "El Padre Maestro Fr. Benito Jerónimo Feijóo. Estudio sobre su vida y sus obras científicas", Almanaque de la Ilustración para el año de 1888. Año XV, Madrid, Establecimiento Tipográfico "Sucesores de Rivadeneyra", 1887, págs. 10-22.

Zaragoza Pascual, Ernesto, "Un abadologio inédito de Samos, del siglo xvIII", Stvdia Monástica, XXII/2 (1980), Barcelona, Abadía de Montserrat, págs. 307-343.

Zaragoza Pascual, Ernesto, "Visitas de los Generales de Valladolid al monasterio de Samos (1698-1832)", Yermo. Cuadernos de historia y de espiritualidad monásticas, vol. 20, núms. 1-2 (1982), Madrid, Monasterio de Santa María del Paular, págs. 37-68.

Zaragoza i Pascual, Ernest, "Libros de gradas de benedictinos profesos en los monasterios de Lorenzana y Samos (1597-1834)”, Estudios Mindonienses, VI (1990), Ferrol (La Coruña), págs. 857-884.

Zaragoza Pascual, Ernesto, “Abadologio del monasterio de San Julián de Samos (siglos VIII-XX)”, Estudios Mindonienses, XII (1996), Ferrol (La Coruña), págs. 469-503. 